\title{
Mechanically Strong Silica-Silk Fibroin Bioaerogel: A Hybrid Scaffold with Ordered Honeycomb Micromorphology and Multiscale Porosity for Bone Regeneration
}

Maleki, Hajar; Shahbazi, Mohammad-Ali; Montes, Susan; Hosseini, Seyed Hojjat; Eskandari, Mohammad Reza; Zaunschirm, Stefan; Verwanger, Thomas; Mathur, Sanjay; Milow, Barbara; Krammer, Barbara Total number of authors:

11

Published in:

ACS Applied Materials and Interfaces

Link to article, DOI:

10.1021/acsami.9b04283

Publication date:

2019

Document Version

Peer reviewed version

Link back to DTU Orbit

Citation (APA):

Maleki, H., Shahbazi, M-A., Montes, S., Hosseini, S. H., Eskandari, M. R., Zaunschirm, S., Verwanger, T., Mathur, S., Milow, B., Krammer, B., \& Hüsing, N. (2019). Mechanically Strong Silica-Silk Fibroin Bioaerogel: A Hybrid Scaffold with Ordered Honeycomb Micromorphology and Multiscale Porosity for Bone Regeneration. ACS Applied Materials and Interfaces, 11(19), 17256-17269. https://doi.org/10.1021/acsami.9b04283

\section{General rights}

Copyright and moral rights for the publications made accessible in the public portal are retained by the authors and/or other copyright owners and it is a condition of accessing publications that users recognise and abide by the legal requirements associated with these rights.

- Users may download and print one copy of any publication from the public portal for the purpose of private study or research.

- You may not further distribute the material or use it for any profit-making activity or commercial gain

- You may freely distribute the URL identifying the publication in the public portal 
See discussions, stats, and author profiles for this publication at: https://www.researchgate.net/publication/332596290

\section{Mechanically Strong Silica-Silk Fibroin Bioaerogel: A Hybrid Scaffold with Ordered Honeycomb Micromorphology and Multiscale Porosity for Bone Regeneration}

Article in ACS Applied Materials \& Interfaces · April 2019

DOI: $10.1021 /$ acsami.9b04283

CITATIONS

14

11 authors, including

Hajar Maleki

University of Cologne

38 PUBLICATIONS 1,157 CITATIONS

SEE PROFILE

Susan K. Montes G.

University of Salzburg

3 PUBLICATIONS 43 CITATIONS

SEE PROFILE
READS

657

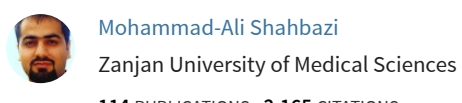

114 PUBLICATIONS 2,165 CITATIONS

SEE PROFILE

Seyed Hojjat Hosseini

Zanjan University of Medical Sciences

22 PUBLICATIONS 115 CITATIONS

SEE PROFILE

Some of the authors of this publication are also working on these related projects:

Molecular Routes to Two-Dimensional Metal Dichalcogenides MX 2 ( $M=$ Mo, W; X = S, Se) View project

FP7-NANOMMUNE; FP7-MARINA; and Flagship Project GRAPHENE View project 


\title{
Mechanically Strong Silica-Silk Fibroin Bioaerogel: A Hybrid Scaffold with Ordered Honeycomb Micromorphology and Multiscale Porosity for Bone Regeneration
}

\author{
Hajar Maleki, ${ }^{*} \dagger \odot$ Mohammad-Ali Shahbazi, ${ }^{*},{ }^{\ddagger}{ }^{\dagger}$ Susan Montes, ${ }^{\perp}$ Seyed Hojjat Hosseini, ${ }^{\#}$ \\ Mohammad Reza Eskandari," Stefan Zaunschirm, ${ }^{\nabla}$ Thomas Verwanger, ${ }^{\bigcirc}$ Sanjay Mathur, ${ }^{\dagger}$ \\ Barbara Milow, ${ }^{\dagger}>$ Barbara Krammer, ${ }^{\nabla}$ and Nicola Hüsing ${ }^{\perp}(\mathbb{0}$
}

${ }^{\dagger}$ Institute of Inorganic Chemistry, Department of Chemistry, University of Cologne, Greinstraße 6, 50939 Cologne, Germany

${ }^{\ddagger}$ Department of Micro- and Nanotechnology, Technical University of Denmark, DK-2800 Kgs Lyngby, Denmark

${ }^{\S}$ Department of Pharmaceutical Nanotechnology, School of Pharmacy and \# Department of Pharmacology and Toxicology, School of Pharmacy, Zanjan University of Medical Sciences, 45139-56184 Zanjan, Iran

${ }^{\perp}$ Department of Chemistry and Physics of Materials, Paris-Lodron University of Salzburg, Jakob-Haringerstr. 2A, 5020 Salzburg, Austria

"Department of Pharmacology, School of Medicine, Zanjan University of Medical Sciences, 45139-56111 Zanjan, Iran

${ }^{\nabla}$ University of Applied Sciences Upper Austria, Franz-Fritsch-Straße 11, 4600 Wels, Austria

ODepartment of Biosciences, Paris-Lodron University of Salzburg, Hellbrunnerstr. 34, 5020 Salzburg, Austria

Department of Aerogels and Aerogel Composites, Institute of Materials Research, German Aerospace Center (DLR), Linder Höhe, 51147 Cologne, Germany

Supporting Information

\begin{abstract}
Due to the synergic feature of individual components in hybrid (nano)biomaterials, their application in regenerative medicine has drawn significant attention. Aiming to address all the current challenges of aerogel as a potent scaffold in bone tissue engineering application, we adopted a novel synthesis approach to synergistically improve the pore size regime and mechanical strength in the aerogel. The three-dimensional aerogel scaffold in this study has been synthesized through a versatile one-pot aqueous-based sol-gel hybridization/assembly of organosilane (tetraethyl orthosilicate) and silk fibroin (SF) biopolymer, followed by unidirectional freeze-casting of the as-prepared hybrid gel and supercritical drying. The developed ultralight silica-SF aerogel hybrids demonstrated a hierarchically organized porous structure with interesting honeycomb-shaped micromorphology and microstructural alignment (anisotropy) in varied length scales. The average macropore size of the hybrid aerogel lied

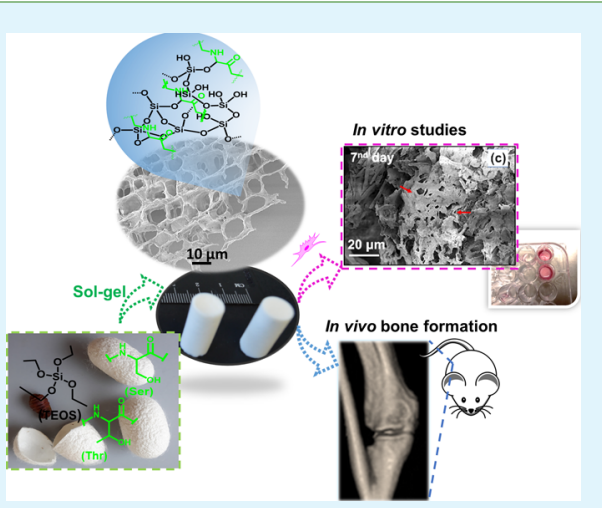
in $\sim 0.5-18 \mu \mathrm{m}$ and was systematically controlled with freeze-casting conditions. Together with high porosity (91-94\%), high Young's modulus ( 4-7 MPa, $>3$ order of magnitude improvement compared to their pristine aerogel counterparts), and bone-type anisotropy in the mechanical compressive behavior, the silica-SF hybrid aerogel of this study acted as a very competent scaffold for bone tissue formation. The results of in vitro assessments revealed that the silica-SF aerogel is not only cytocompatible and nonhemolytic but also acted as an open porous microenvironment to trigger osteoblast cell attachment, growth, and proliferation on its surface within 14 days of incubation. Moreover, to support the in vitro results, in vivo bone formation within the aerogel implant in the bone defect site was studied. The X-ray radiology and microcomputed tomography analyses confirmed that a significant new bone tissue density formed in the defect site within 25 days of implantation. Also, in vivo toxicology studies showed a zero-toxic impact of the aerogel implant on the blood biochemical and hematological parameters. Finally, the study clearly shows the potential of aerogel as a bioactive and osteoconductive open porous cellular matrix for a successful osseointegration process.
\end{abstract}

KEYWORDS: silica, silk fibroin, hybrid aerogel, sol-gel, bone tissue engineering

\section{INTRODUCTION}

Bone tissue engineering (BTE) is an alternative approach to current therapies available for severe bone defects with poor manifestations of self-regeneration. ${ }^{1}$ Accomplishment of BTE
Received: March 9, 2019

Accepted: April 23, 2019

Published: April 23, 2019 


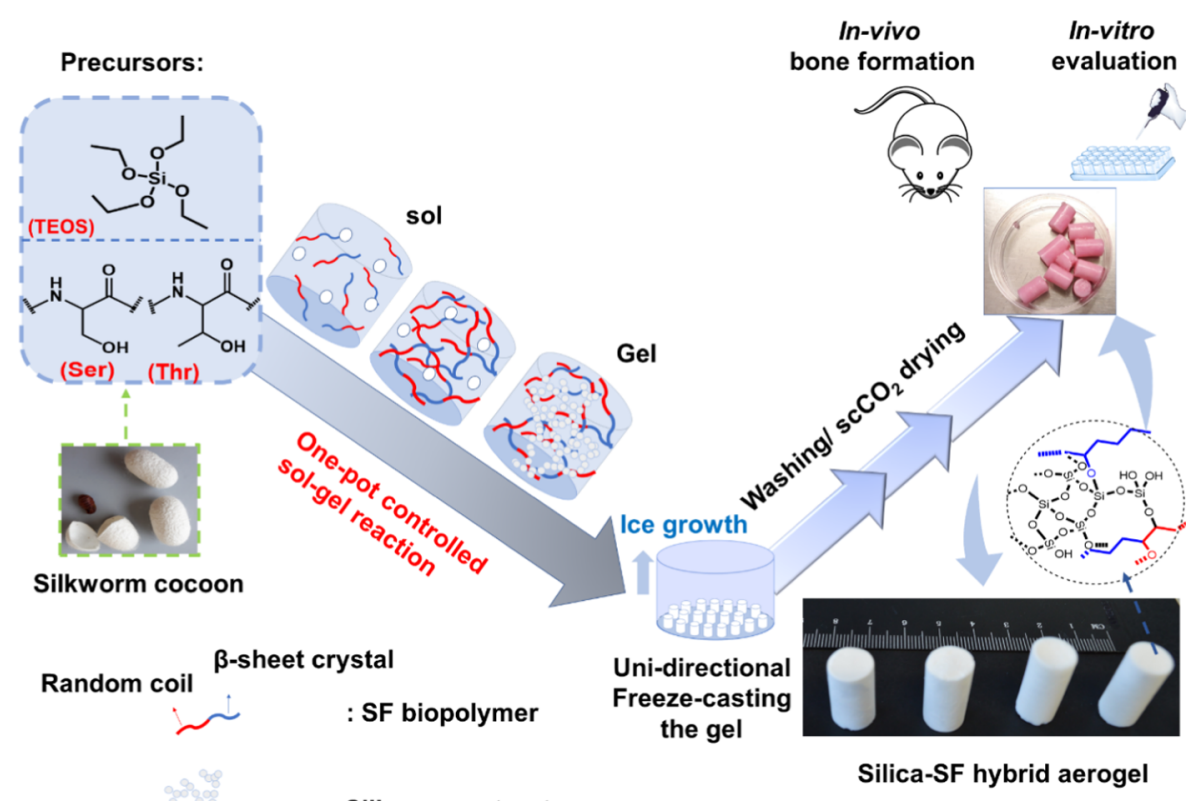

: Silica nanostructure

Figure 1. Schematic illustration of the synthesis procedure for the silica-SF aerogel hybrid scaffold through sol-gel reaction, unidirectional freezecasting, and supercritical drying approach.

needs three-dimensional (3D) templates (scaffolds) of appropriate morphology and chemical characteristics to imitate the extracellular matrix (ECM) and allow cells to migrate, attach, grow, proliferate, and differentiate. ${ }^{2}$ A variety of materials, such as synthetic and natural polymers, ceramics, and hybrid materials, as well as various manufacturing technologies have been employed to develop scaffolds with the aim of resembling physicomechanical and biological properties of the bone tissue. Along with biocompatibility and biodegradability, an ideal scaffold for BTE needs a series of requirements in terms of (micro)structural functions. Considering a porous structure as an example, it is revealed that micron-sized pores $(20-1500 \mu \mathrm{m})^{3}$ are required for cell ingrowth, spreading, and proliferation, whereas nanosized porous struts impart mechanical stability (desired is 5-10 $\mathrm{MPa}$ for compressive strength), flexibility, nutrition delivery, signaling communication of cells, and excrements' removal., In addition, hierarchically organized porosity is particularly advantageous for in vivo neovascularization and proper cell attachment across the scaffold. The large internal surface contributed by primarily micro- and mesoporous struts also favors protein adsorption, ion exchange, and formation of the hydroxyapatite (HAp)-rich cement line in the early stadium of osteoconduction. ${ }^{6}$

Silk fibroin (SF), a protein-based biopolymer with plenty of tissue-like features and high biocompatibility, controlled degradability, favorable mechanical strength, and processability to various material forms, has been widely explored as the backbone of BTE scaffolds. ${ }^{7,8}$ Injectable gels, ${ }^{9}$ freeze-dried ${ }^{9}$ or progene-leached sponges, ${ }^{9,10}$ electrospun ${ }^{11}$ and 3D printed constructs, ${ }^{12,13}$ and composites with (bio)-inorganic materials $^{14}$ are the most studied constructs of SF for cell colonization and proliferation in vitro and in vivo. ${ }^{15}$ However, SF processing into ultralight and resilient aerogel, the so-called AeroSF, with hierarchical porosity through successful implementation of the sol-gel reaction and the green supercritical $\mathrm{CO}_{2}$ drying approach, has recently been reported in our group. ${ }^{16}$ The reported AeroSF is hypothesized to become a potent biomaterial for the BTE as it provides improved mechanical feature and osteoconductivity.

Aerogels are 3D porous nanostructured materials with exceptional physical properties, such as extremely low densities $\left(0.003-0.5 \mathrm{~g} \mathrm{~cm}^{-3}\right)$, high specific surface areas $\left(100-1200 \mathrm{~m}^{2}\right.$ $\left.\mathrm{g}^{-1}\right)$, high porosities (80-99.9\%), and tunable surface and bulk chemistries. $^{17,18}$ Thanks to these promising features, they can be considered interesting, supportive templates for bone formation. However, the lack of micron-sized porosity and poor mechanical strength combined with poor machinability or shaping to a sophisticated construct are still important bottlenecks, which should be mitigated to achieve a real breakthrough in aerogel-mediated BTE. ${ }^{6,8}$ Therefore, further research on aerogels is required to (1) develop robust processing techniques to confer controlled macroporosity to aerogel for host cell colonization, (2) improve the aerogel synthesis method to achieve a mechanically strong scaffold that can temporarily substitute natural tissues without compromising the biocompatibility of the materials, and (3) allow the incorporation of bioactive compounds (e.g., growth factor) in high yields to impart bioactivity to respective scaffolds and promote new tissue growth. ${ }^{19-26}$

For an efficient mechanical reinforcement in the silica $\left(\mathrm{SiO}_{2}\right)$ aerogel, as a principal constituent of the novel scaffold of the current work, several strategies have been implemented. ${ }^{16,26,27}$ Among them, synthesis of mechanically robust hybrid aerogels with an interpenetrating network (IPN) consisting of sustainable biopolymers, such as polysaccharides and proteins, to impart some mechanical resiliency to the delicate inorganic silica ${ }^{16,27}$ and polysilsesquioxane $\left(\left[\mathrm{RSiO}_{3 / 2}\right]_{n}\right)^{28,29}$ structures has been drawing tremendous attention. We recently synthesized hybrid aerogels with an IPN structure by combining the intriguing features of the SF biopolymer with those peculiar physical properties in silica and silsesquioxane aerogels that reflect the properties of both initial constituents. $^{16,30}$ Versatile in situ sol-gel reaction of the SF 
solution with the organosilane phase was conducted through precise control on the gelation kinetics and phase separation to form a covalently bonded IPN structure at a molecular scale. $^{16,28}$

Various ways have been described in the literature to impart micron-sized porosity to the bone scaffolds. ${ }^{31}$ Among the techniques like phase separation (soft) and template sacrification (hard), emulsion, and gas foaming, the unidirectional freeze-casting or ice-templating method proved to function well. ${ }^{1,31}$ The unidirectional nucleation and growth of the ice crystals, as a green template, by applying a temperature gradient in the gel body not only provide the macroporosity but also render the gel with a valuable bonetype anisotropy or an ordered honeycomb-like microstructure. ${ }^{32}$ The anisotropic scaffold structure is further asset for the cell guidance, differentiation, biofactor and nutrient transferring, and the bone vessel formations within the final scaffold. ${ }^{32-36}$ Also, the alignment of the microstructure in the gel body toward the ice growth direction would not compromise the mechanical integrity in the scaffold as the other harsh, hard templating techniques do. ${ }^{37}$

Herein, we aim to develop a multiscale porous hybrid silicasilk fibroin aerogel-based scaffold through in situ processing of tetraethyl orthosilicate (TEOS) with the SF biopolymer in an entirely aqueous-based sol-gel reaction, followed by unidirectional freeze-casting and then by $\mathrm{CO}_{2}$ supercritical drying $\left(\mathrm{scCO}_{2}\right)$ (Figure 1 ). In our proposed fabrication method, SF possesses high mechanical resiliency and supports the compressive and bending flexibility in the final scaffold as an organic extracellular bony matrix. On the other hand, the nanostructured silica renders mechanical stiffness like inorganic reinforcement or filler as observed in the bone. Moreover, proven osteoconductivity in nanostructured sili$\mathrm{ca}^{38,39}$ is speculated to equip the SF with bioactivity and cell adhesion feature, compensating the SF deficiency for arginineglycine-aspartic acid (RGD) integrin, a peptide motif responsible for cell attachment to the ECM. Robust analogizing of the sol-gel reaction with unidirectional freezecasting could successfully improve the macroporosity, mechanical strength, and anisotropy in the microstructure with establishing a structure-property relationship in the final aerogel scaffold. The final 3D composite scaffold was not only biocompatible but also highly osteoconductive and promoted new bone formation in vitro and in vivo.

\section{MATERIALS AND METHODS}

2.1. Materials. All chemicals in this study were used without purification. The Bombyx mori silkworm cocoons were purchased from Wild Fibers, U.K. Tetraethyl orthosilicate ( $98 \%$ purity, TEOS), hexadecyltrimethylammonium bromide (98\% purity, CTAB), methanol $(99.8 \%, \mathrm{MeOH})$, ethanol $(99.9 \%, \mathrm{EtOH})$, lithium bromide ( $\mathrm{LiBr}$ ) anhydrous, (99.99\% purity, $\mathrm{LiBr})$, sodium carbonate $\left(\mathrm{Na}_{2} \mathrm{CO}_{3}\right)$, 3-(4,5-dimethyl-2-thiazolyl)-2,5-diphenyl-2H-tetrazolium bromide (MTT), Hoechst 33342, Dulbecco's modified Eagle's medium (DMEM), fetal bovine serum (FBS), Dulbecco's phosphate-buffered saline (DPBS), trypsin, Triton X-100, ammonium molybdate tetrahydrate $\left(\left(\mathrm{NH}_{4}\right)_{6} \mathrm{Mo}_{7} \mathrm{O}_{24}\right)$, oxalic acid $\left(\mathrm{C}_{2} \mathrm{H}_{2} \mathrm{O}_{4}\right), 4$ methylaminophenol sulfate, anhydrous sodium sulfite $\left(\mathrm{Na}_{2} \mathrm{SO}_{3}\right)$, and sulfuric acid were received from Sigma-Aldrich. Bicinchoninic acid (BCA)-reagent A and Slide-A-Lyzer Dialysis Cassettes with molecular weight cutoffs of $3.5 \mathrm{kDa}$ and a volume capacity of $3.5-5 \mathrm{~mL}$ were purchased from Thermo Fisher Scientific.

2.2. Silk Fibroin Extraction. The SF aqueous solution was extracted from silkworm cocoons through a slightly modified procedure reported in Nature Protocols by Kaplan et al. ${ }^{15}$ First, silk cocoons $(5 \mathrm{~g})$ were cut into dime-sized pieces and boiled for $30 \mathrm{~min}$ in a $2 \mathrm{~L}$ solution of $\mathrm{Na}_{2} \mathrm{CO}_{3}(0.02 \mathrm{M})$; then, fibers were rinsed with plenty of ultrapure water and dried overnight. The dry silk fibers were dissolved in $\mathrm{LiBr}(12-15 \mathrm{M})$ solution at $60{ }^{\circ} \mathrm{C}$ for $4 \mathrm{~h}$ and then dialyzed against ultrapure water for $48 \mathrm{~h}$. The dialyzed SF solution was centrifuged at $9000 \mathrm{rpm}$ twice, and the supernatant was stored at $4{ }^{\circ} \mathrm{C}$ for later use.

2.3. Preparation of Unidirectional Freeze-Cast Silica-SF Aerogel Hybrid Scaffold. 2.3.1. Preparation of Silica-Silk Fibroin As-Prepared Gel. To obtain silica-SF composites, we adopted a onestep/one-pot acid-catalyzed sol-gel approach (cf. Figure 1) in which a sol with a total volume of $5 \mathrm{~mL}$ is prepared comprising organosilane (tetraethyl orthosilicate, TEOS, $3.37 \mathrm{mmol}, 0.5 \mathrm{~mL}$ ), SF biopolymer $(4 \mathrm{~mL}, 4 \% \mathrm{w} / \mathrm{v})$ in an aqueous acetic acid solvent $(0.5 \mathrm{~mL}, 120 \mathrm{mM})$, and $\mathrm{CTAB}(0.5 \mathrm{~g})$. In the total sol mixture, the SF to silane mass fractions were 32:100. A homogeneous composite gel of silica-silk fibroin hybrid was formed in the ventilation oven $\left(40^{\circ} \mathrm{C}\right)$ within $1 \mathrm{~h}$ to complete the hydrolysis and condensation reaction of the silane phase and the sol-gel reaction at the SF component, but also establishing some covalent and noncovalent interactions of both components at the molecular state.

2.3.2. Preparation of the Silk Fibroin As-Prepared Gel. The SFbased hydrogel was prepared according to our previous works, ${ }^{16,28}$ which is briefly explained here. A mixture solution $(5 \mathrm{~mL})$ of SF $(4$ $\mathrm{mL}, 4 \% \mathrm{w} / \mathrm{v})$ and acetic acid $(1 \mathrm{~mL}, 10 \mathrm{mM})$ was prepared. The solution was stirred for 15 min until a very low viscose gelly solution was obtained. Then, the viscose solution was transferred to the poly(tetrafluoroethylene) mold to complete the gelation in a ventilation oven $\left(40{ }^{\circ} \mathrm{C}, 4 \mathrm{~h}\right)$.

2.3.3. Unidirectional Freeze-Casting or Ice Templating the AsPrepared Silica-SF Gel. The as-prepared weak hydrogels with interpenetrating networks underwent unidirectional freeze-casting according to the modified procedure reported by Nishihara et al. ${ }^{40}$ Freeze-casting was performed through immersing the cylindrical gel unidirectionally at a constant rate of $V_{\mathrm{f}}\left(33\right.$ and $\left.66 \mathrm{~cm} \mathrm{~h}^{-1}\right)$ into a cold bath maintained at a constant temperature of $T_{\mathrm{f}}\left(-10\right.$ and $\left.-197^{\circ} \mathrm{C}\right)$. The resulted sample has been designated as silica-SF- $T_{\mathrm{f}}-V_{\mathrm{f}}$ in Table 1 . The ice growth was initiated from the bottom of the tube and continued until the tube was completely frozen. Afterward, the sample was transferred into a cold bath maintained at $0{ }^{\circ} \mathrm{C}$ for $2 \mathrm{~h}$ to preserve the ice rod template in the gel to strengthen the structure and preserve the created semi-microhoneycomb-shaped structural pattern. After this low-temperature aging, the sample was thawed at room temperature, $23{ }^{\circ} \mathrm{C}$, for $0.5 \mathrm{~h}$. The thawed samples were transferred into the oven at $40{ }^{\circ} \mathrm{C}$ for $48 \mathrm{~h}$ to continue aging and allow finalization of the rest of the sol-gel reaction in the gel. Next, samples were washed four times at $8 \mathrm{~h}$ intervals with ethanol to remove CTAB and unreacted precursors and treated with a 70:30 (v/v) methanol/ ethanol mixture and finally transferred into $\mathrm{scCO}_{2}$ autoclave and supercritically dried.

The same directional freeze-casting approach was also applied for the SF-based hydrogel.

2.4. Chemical, Biophysical, and Mechanical Properties of the Aerogel. Solid-state ${ }^{29} \mathrm{Si}$ and ${ }^{1} \mathrm{H}$ NMR spectra of the aerogels were obtained by using an Inova 500 spectrometer using a $4 \mathrm{~mm}$ solid probe with cross-polarization (CP) and magic angle spinning (MAS) at $11 \mathrm{kHz}$. A solid-state ${ }^{1} \mathrm{H}-{ }^{29} \mathrm{Si}$ heteronuclear correlation (HETCOR) NMR spectrum was collected using $4 \mathrm{~mm}$ zirconia rotors with a spinning rate of $11 \mathrm{kHz}$ and applying homonuclear decoupling using continuous phase modulation (DUMBO) to increase the ${ }^{1} \mathrm{H}$ spectral resolution. Transmission electron microscopy (TEM) images were recorded with a JEOL 200F cold field-emission (W) filament, $200 \mathrm{keV}$, operated at an accelerating voltage of $300 \mathrm{kV}$. Energy-dispersive spectroscopy (EDS)-TEM-elemental mappings were recorded by JEOL, Centurio 100, with a detector area of 100 $\mathrm{mm}$, solid angle of $0.97 \mathrm{sr}$, and resolution of $\sim 133 \mathrm{eV}$ for $\mathrm{Mn}$. Scanning electron microscopy (SEM) images were taken with a scanning electron microscope (Zeiss ULTRA Plus) running at $5 \mathrm{kV}$ with an in-lens detector and a working distance of around $4 \mathrm{~mm}$. SEM energy-dispersive X-ray (EDX) spectra were taken by the same 
microscope running at $15 \mathrm{kV}$ and a working distance of around $9 \mathrm{~mm}$. For X-ray microcomputed tomography $(\mu$-CT) data, the sample was scanned with RX solutions (EasyTom 160) using a $4032 \times 2688$ charge-coupled device camera (XIMEA, Germany) and a $\mathrm{LaB}_{6}$ filament working at $50 \mathrm{kV}$ voltage, $90 \mu \mathrm{A}$ current, $750 \mathrm{~ms}$ integration time, averaging 6 , and 3488 projections. The bulk density was calculated from the corresponding mass and volume of the cylindrical aerogel. Nitrogen adsorption-desorption measurements were carried out at $77 \mathrm{~K}$ using Micromeritics ASAP 2420. Before analysis, the sample was outgassed at $60{ }^{\circ} \mathrm{C}$ in vacuum (10-5 bar) for $24 \mathrm{~h}$ to remove adsorbed species. The skeletal density was measured using a helium pycnometer (AccuPyc II 1340, Micromeritics). From the skeleton and bulk density values, the porosity $\varepsilon(\%)(1)$, pore volume $\left(V_{\mathrm{p}}\right)(2)$, and pore diameter $\left(D_{\mathrm{p}}\right)(3)$ of the samples were calculated according to the following equations:

$$
\begin{aligned}
& \text { porosity, } \varepsilon(\%)=\frac{1 / \rho_{\mathrm{b}}-1 / \rho_{\mathrm{s}}}{1 / \rho_{\mathrm{b}}} \times 100 \\
& \text { pore volume, } V_{\text {pore }}\left(\mathrm{cm}^{3} \mathrm{~g}^{-1}\right)=\left(1 / \rho_{\mathrm{b}}-1 / \rho_{\mathrm{s}}\right) \\
& \text { pore diameter, } D_{\text {pore }}(\mathrm{nm})=4 V_{\mathrm{p}} / S_{\mathrm{BET}}
\end{aligned}
$$

The specific surface area was calculated with the Brunauer, Emmett, and Teller five-point method in the relative pressure range of 0.050.3. Mechanical characterization of the composites was carried out on the monolithic cylindrical samples using a universal mechanical testing equipment (Zwick/Z010, Zwick/Roell, Germany) equipped with a $1 \mathrm{kN}$ force transducer (KAP-S, AST Gruppe GmbH, Germany) in a controlled environment $\left(23^{\circ} \mathrm{C}, 50 \%\right)$.

2.5. Cell Lines, Culture Conditions, and Scaffold Preparation Conditions. The human osteosarcoma MG-63 cell line (ATCC CRL-1427) was cultured in DMEM supplemented with fetal calf serum (10\% FBS), $100 \mathrm{U} \mathrm{mL}^{-1}$ penicillin, and $0.1 \mathrm{mg} \mathrm{mL}-1$ streptomycin. The cultures were maintained in a humidified incubator at $37{ }^{\circ} \mathrm{C}$ with $5 \% \mathrm{CO}_{2}$.

The aerogel scaffolds $(6 \mathrm{~mm}$ diameter $\times 1 \mathrm{~cm}$ height $)$ were treated with graded ethanol $(100,70,50$, and $20 \%, 30$ min each treatment) to sterilize them. The matrixes were then washed with excess $1 \times$ Dulbecco's phosphate-buffer saline (DPBS) ( $\mathrm{pH}$ 7.4) three times, 15 min each, for complete removal of the ethanol. After washing, the sterilized aerogel scaffold was incubated in complete culture media to precondition them for boosting cell attachment and the biocompatibility test. For the cell seeding test, the excess media was removed by squeezing the scaffold very gently prior to cell seeding to soak the cell suspension without letting them float around.

2.6. Cell Viability. Indirect MTT assay was performed to test the cytotoxicity of the scaffold's degradation or leaching products for 14 days. Prior to the test, the sterilized aerogel scaffolds were immersed in DMEM $+10 \%$ FBS and antibiotics for each time point (five time points, three replications) at $37{ }^{\circ} \mathrm{C}$ in $5 \% \mathrm{CO}_{2}$. Also, blank medium (negative control) was incubated in the same condition for 14 days. Next, $100 \mu \mathrm{L}$ with 30000 cells was seeded in fresh DMEM $+10 \%$ FBS in each well in a 96-well plate for $24 \mathrm{~h}$. At each time point (days $1,3,7,10$, and 14), the medium of each well, containing cells, was exchanged with $100 \mu \mathrm{L}$ of scaffold, blank, or fresh medium (DMEM + $10 \% \mathrm{FBS}$ ) and incubated for $48 \mathrm{~h}$. Afterward, MTT staining solution ( $10 \mu \mathrm{L}, 5 \mathrm{mg} \mathrm{mL}^{-1}$ in DPBS) was added to the cell culture medium of the sample, negative control, and fresh medium and incubated for 1.5 $\mathrm{h}$ at $37^{\circ} \mathrm{C}$. Next, the MTT solution was discarded, and $100 \mu \mathrm{L}$ of isopropanol was added to lyse the cells. After $5 \mathrm{~min}$ of shaking, the absorption at $565 \mathrm{~nm}$ was measured on a TECAN Infinite M200 PRO microplate reader.

2.7. Visualization of Cellular Attachment. The cell morphology and attachment on the aerogel scaffold were tested by scanning electron microscopy (SEM) and inverted fluorescence microscopy (Olympus IX70). The sterilized aerogel samples were put in 48-well plates. Then, 500000 cells were counted and added to each well followed by medium replacement every $48 \mathrm{~h}$. At each time point (days $1,3,7$, and 14), the samples were taken out of the culture medium, 
washed with DPBS ( $\mathrm{pH}$ 7.4) three times, and fixed by $2.5 \%$ glutaraldehyde (in DPBS) at $37{ }^{\circ} \mathrm{C}$ for $1 \mathrm{~h}$. After that, the samples were dehydrated with different concentrations of ethanol $(50,70,96$, and $100 \%$ ) and finally vacuum-dried. The dried aerogel samples were then sputtered with gold and analyzed with SEM. For fluorescence microscopy, the DNA of the fixed cells attached to the scaffold was stained with Hoechst $33342\left(10 \mu \mathrm{g} \mathrm{mL}^{-1}\right.$ in DMEM) and incubated for $15 \mathrm{~min}$ at $37{ }^{\circ} \mathrm{C}$ in dark. Afterward, the samples were washed twice with DPBS, and cell nuclei were visualized by fluorescence microscopy.

2.8. Hemolysis Assay. Fresh human blood samples stabilized by heparin were obtained from anonymous donors with the permission of the respective institutional ethical committee. Within $2 \mathrm{~h}$ after blood sampling, red blood cells (RBCs) were isolated by mixing $5 \mathrm{~mL}$ of blood with $10 \mathrm{~mL}$ of DPBS and centrifugation at $2500 \mathrm{rpm}$ for 6 min. This step was repeated five times to obtain an RBC pellet. Next, $5 \%$ hematocrit (HCT) suspension was obtained by mixing $1 \mathrm{~mL}$ of the RBC pellet with $19 \mathrm{~mL}$ of DPBS. The hemolytic effect of the scaffold was investigated by adding $200 \mu \mathrm{L}$ of the $5 \%$ hematocrit to $800 \mu \mathrm{L}$ of the different concentrations of scaffold powder in DPBS to reach the final concentrations of $100,200,400,800$, and $1200 \mu \mathrm{g}$ $\mathrm{mL}^{-1}$. Each of the samples was vortexed for $5 \mathrm{~s}$ and subsequently incubated at room temperature for $2,4,8$, and $24 \mathrm{~h}$. In each time point, the samples were gently vortexed for $5 \mathrm{~s}$ and centrifuged at 13 $000 \mathrm{rpm}$ for $3 \mathrm{~min}$. Afterward, $100 \mu \mathrm{L}$ of the supernatant was withdrawn to 96-well plates (Corning Inc., Life Sciences), followed by quantification of the lysed hemoglobin (HGB) at $577 \mathrm{~nm}$ using a Varioskan Flash Multimode Microplate Reader (Thermo Fisher Scientific Inc.). Milli-Q water was used as the positive control with $100 \%$ of RBC lysis effect. The results represent the average of, at least, three independent experiments.

2.9. In Vivo Radiography, $\mu$-CT Analysis, and Toxicity Assessment during Bone Formation. The animal experiments were approved by the Animal Ethical Committee of Zanjan University of Medical Sciences. The osteogenic support of the developed scaffold was studied on healthy Sprague Dawley male rats weighing 310-335 g. Fifteen rats were equally divided into three groups. The first group was control without any bone defect and scaffold implantation. The other two groups were (1) animals with bone defect induction in the femur but without scaffold implantation and (2) animals with bone defect induction in the femur and with scaffold implantation. Bone defects were similar in all animals, and the scaffolds were implanted at the defect site by the press-fit method for 25 day monitoring of the bone formation and 60 day toxicity assessment. For radiological and $\mu$-CT analyses (Phoenix vjtomejx s, GE, Germany), the animals were euthanized, and femurs were removed from all the three groups and subjected to radiological and $\mu$-CT experimentations. Macroscopic photos of regenerated sites were also taken on 25 days postimplantation. These studies were performed to investigate the regeneration of bone and tissue ingrowth, position of the implant inside bone, and scaffold interaction with the host bone over the wound closure time. The X-ray imaging was under the condition of 75 $\mathrm{mA}, 85 \mathrm{kV}, 500 \mathrm{~ms}$ per slice, and voxel size $26 \mathrm{~mm}$. For the in vivo toxicity test, blood collection from the animals was performed after 1 , $15,30,45$, and 60 days of scaffold implantation for the analysis of the different biochemical and hematological parameters. The blood analysis was performed within $4 \mathrm{~h}$ postsampling, and the plasma biochemistry studies were conducted on the same day of the blood collection. In all in vivo studies, all animals were kept in a ventilated temperature-controlled animal room 5 days before starting the experiments. The relative humidity of $60 \pm 10 \%$ and a $12 \mathrm{~h}$ light/dark daily cycle were applied in the animal room. During the studies, standard polycarbonate stainless steel wire-topped cages were used for housing the animals, and free access to rat chow and water ad libitum were provided.

2.10. Statistical Analysis. The results are expressed as mean \pm standard deviations (SD) of at least three independent sets of measurements. Statistical analysis was achieved by means of one-way and two-way analyses of variance with the level of significance set at probabilities of $* p<0.05$, $* * p<0.01$, and $* * * p<0.001$, analyzed with GraphPad Prism 7 software.

\section{RESULTS AND DISCUSSION}

3.1. Physical, Microstructural, and Mechanical Characteristics of the Scaffold. In this study, the in situ acidcatalyzed sol-gel reaction associated with the unidirectional freeze-casting approach has been implemented on the silica-SF gel for producing anisotropic multiscale porous aerogels. According to Figure 1, when silica-SF hybrid hydrogels, which are freshly gelled and have enough amount of the solid phase, are frozen unidirectionally under a pseudo-steady-state of ice growth condition, an array of phase-separated polygonal ice rods grow in parallel with the freezing direction from the bottom of the gel. This strategy produces frozen gels consisting of anisotropic ice crystals surrounded by the walls formed by the dispersed silica nanoparticles and SF fibers (Figure 1). After removal of the ice template and supercritical drying, monolithic aerogels with almost ordered macropores can be obtained. In the literature, the unidirectional freeze-casting, which uses the ice as the structural directing agent, has been referred to as the ice-segregation-induced self-assembly ${ }^{32,40}$ process, which forms an anisotropic structure from the sol, gel, and various types of slurries like polymers and nanosheets.

According to Table 1, besides sol-gel reaction parameters, the freezing conditions have also a high control on the micromorphology of the resulting gel, such as pore orientation, size, and other physical properties such as the extent of the porosity $\varepsilon(\%)$, specific surface area $\left(S_{\mathrm{BET}}\right)$, and mesopore size regime $\left(D_{\text {pore }}\right)$. The gel obtained by the low cooling rate (33 $\left.\mathrm{cm} \mathrm{h}^{-1}\right)$ and low cooling temperature $\left(-196{ }^{\circ} \mathrm{C}, \mathrm{LN}_{2}\right)$, silicaSF-196-33, has shown bigger macrosized pores $(17.84 \pm 2.75)$ compared to that obtained with a high cooling rate $(66 \mathrm{~cm}$ $\left.\mathrm{h}^{-1}\right)$ and high freezing temperature $\left(-10^{\circ} \mathrm{C}\right)$, silica-SF-10-66 $(0.52 \pm 0.14)$ (cf. Figure S1). This finding is in agreement with the work of Nishihara et al., ${ }^{40}$ who developed silica gel with an ordered macroporous honeycomb-like microstructure with an average macropore size range of $3-40 \mu \mathrm{m}$ under varying freezing conditions. According to their finding, at lower freezing temperatures $\left(T_{\mathrm{f}}\right)$ and lower immersion rate of the gel into the cooling bath $\left(V_{\mathrm{f}}\right)$, bigger macropores in the gel body could be obtained. ${ }^{40}$

Also, all freeze-casted aerogels have indicated a high extent of porosities (91-94\%) with bulk densities $\left(\rho_{\mathrm{b}}\right)$ and Young's modulus $(\varepsilon)$ highly dependent on the freezing direction (cf. Table 1).

The silica-SF-196-33 was the lightest $\left(\rho_{\mathrm{b}}=0.075 \mathrm{~g} \mathrm{~cm}^{-3}\right)$ and the strongest hybrid scaffold $(\varepsilon=7.3 \mathrm{MPa})$ as seen from the data in Table 1 and the stress-strain curve obtained by compressive studies (see also Figure S2). The reported bulk density in silica-SF-196-33 is also lower than that of previously reported open-cell scaffold foams or sponges. ${ }^{41}$ In this aerogel, it is hypothesized that the microstructural alignment caused by unidirectional freezing of the gel has provided a strength toward compressive loads.

Therefore, the silica-SF-196-33 aerogel scaffold, hereafter denoted "silica-SF aerogel scaffold", has been selected as the aerogel with optimal structural and mechanical properties and implemented in detailed characterizations and biological studies.

The internal microstructural pattern, from a multiscale standpoint, has been studied with a combination of scanning electron microscopy (SEM), transmission electron microscopy 

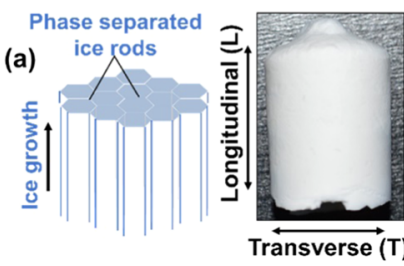

(c)

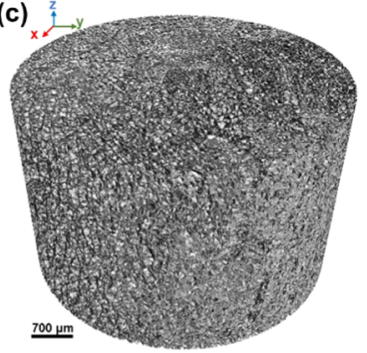

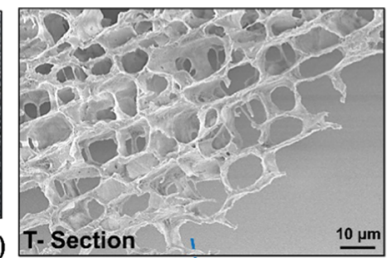
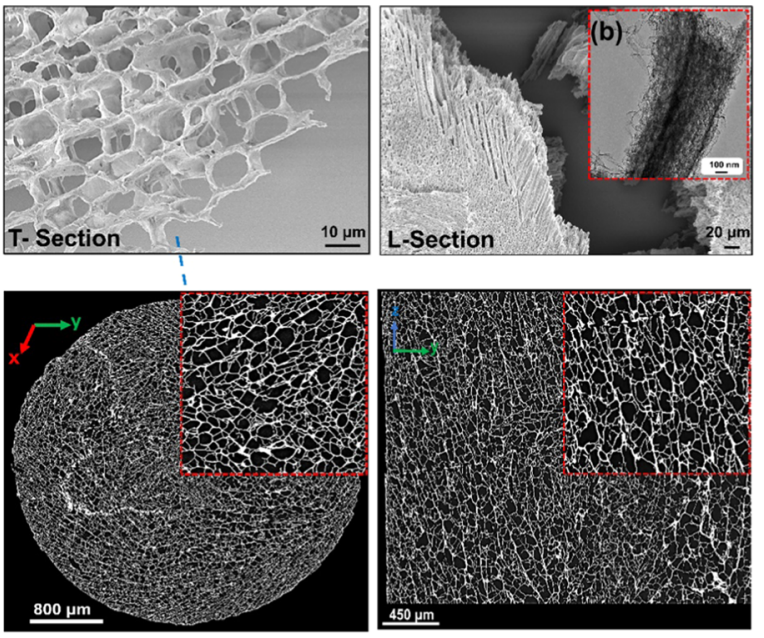

(d)
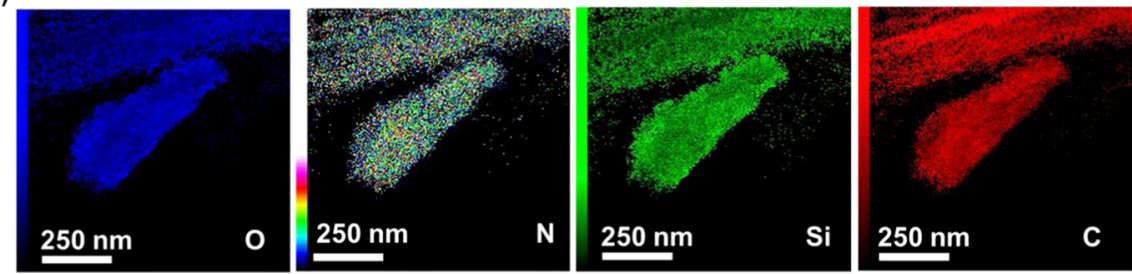

Figure 2. Microstructural and compositional characteristics of the silica-SF aerogel hybrid scaffold with (a) SEM, (b) TEM, (c) $\mu$-CT scans and 3D reconstruction, and (d) TEM-EDX elemental mapping.

(TEM), and X-ray microtomography $(\mu-\mathrm{CT})$ for the silica-SF196-33 aerogel (Figure 2a-c). Figure 2a reveals aligned polygonal pores with a diameter of $\sim 18 \mu \mathrm{m}$ (measured by ImageJ) and a cell wall thickness of $0.4-1.5 \mu \mathrm{m}$ (Figure $2 \mathrm{a}, \mathrm{T}$ section). Since the aligned macropores have a polygonal cross section and are parallel to the freezing direction (Figure 2a, Lsection), we named this micromorphology of the obtained material as microhoneycomb because it resembles a miniaturized honeycomb topological structure. ${ }^{42}$

The microstructural alignment is also notable at low length scales (nanometer) as shown in Figure $2 b$, with uniform distribution of all key network elements $\mathrm{Si}, \mathrm{C}, \mathrm{N}$, and $\mathrm{O}$ as observed with TEM-EDX elemental mapping (Figure $2 \mathrm{~d}$ ). $\mu$ $\mathrm{CT}$ analysis in Figure $2 \mathrm{c}$ reveals that the pores are developed as millimeter-long rods parallel to the freezing direction throughout the material. Cross sections taken at different positions along the ice growth direction show that the pore density is almost the same in all lengths of the sample. However, the pore size slightly decreases toward the center of the material, which could be possibly due to the low thermal contact of the gel center with the ice bath. This suggests that the pore structure is almost uniform with relatively moderate extent of pore interconnectivity. The detailed visual observations of the $3 \mathrm{D}$ scaffold structure are presented in the Supporting Information (Videos S1 and S2).

The stress-strain curves in Figure 3a display the typical deformation behavior of freeze-casted aerogels, i.e., linear elastic behavior at low strain followed by a successive pore collapse-related stress reduction at intermediate strains, and finally a plastic yielding plateau with subsequent strain hardening at high strain. We obtain a Young's modulus of $\varepsilon$ $=7.3 \mathrm{MPa}$ along the pore (freezing) direction (Figure 3a, axial), which is significantly higher than the values for previously reported pristine silk fibroin $(0.09 \mathrm{MPa})^{16}$ and silica aerogels $(5-20 \mathrm{kPa})^{43}$ and comparable to that of recently
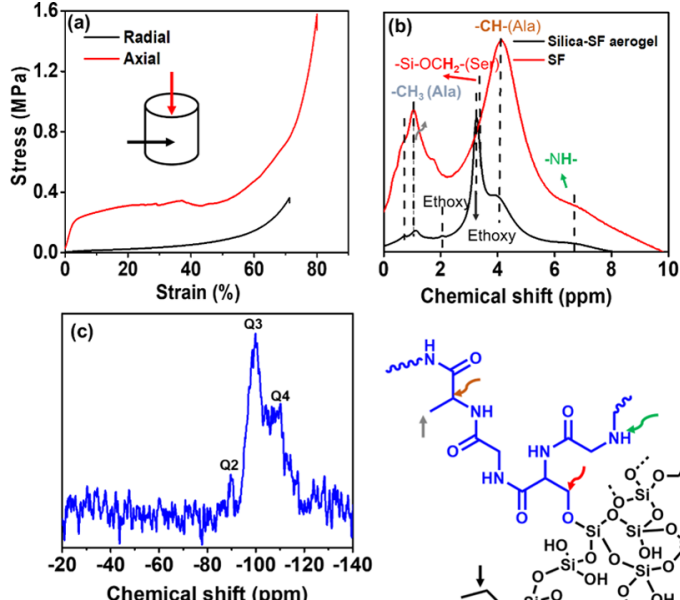<smiles>CNC(=O)C(I)(I)NC(=O)CI</smiles>
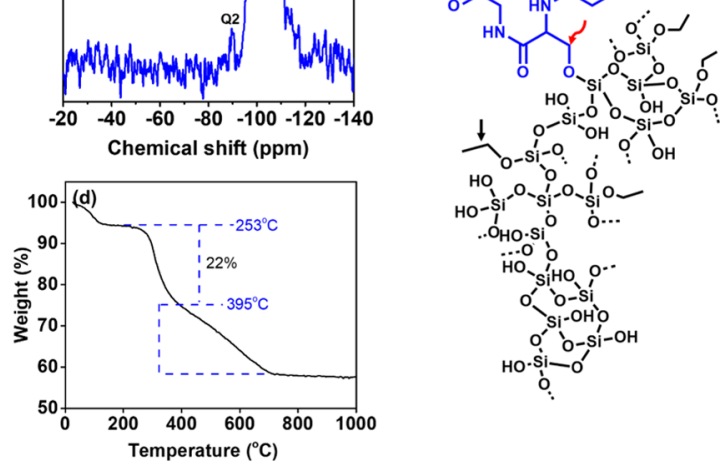

Figure 3. (a) Stress-strain curve, solid-state MAS (b) ${ }^{1} \mathrm{H}$ and (c) ${ }^{29} \mathrm{Si}$ NMR spectroscopies (including the proposed molecular structure of the silica-SF aerogel), and (d) thermogravimetric (TG) analysis of the silica-SF aerogel scaffold. SF aerogel in (b) has undergone the same freezing conditions as the silica-SF aerogel.

reported silk fibroin/carbon nanofiber composites $(\sim 10$ $\mathrm{MPa}){ }^{44}$ This anisotropic mechanical behavior in the scaffolds resembles the anisotropic structure of the bone that is often stronger in the direction with high mechanical load. 
3.2. Scaffold's Chemical Characteristics. The one-pot gelation of the SF biopolymer with (organo)-silane occurs in two steps. First, gelation is induced by assembling the SF in diluted acidic media. The silk fibroin proteins become physically cross-linked/assembled followed by simultaneous hydrolysis and polycondensation of the (organo)-silanes in the second step (cf. Figure 1). However, based on our previous studies, in situ assembly of SF with silanes is very sensitive to the type of the silane precursor as well as to the gelation $\mathrm{pH}$. Processing of the SF with the methyltrimethoxy silane $\left(\mathrm{CH}_{3} \mathrm{Si}\left(\mathrm{OCH}_{3}\right)_{3} \text {, MTMS }\right)^{28}$ precursor resulted in superhydrophobic final materials, whose gelation was hardly controlled due to the polarity differences in sol components as well as in the gelation kinetics of organic and inorganic phases. Although these issues were solved by adding a phase separation suppressing agent to the sol mixture as well as conducting the gelation process in a successive two-step process, the superhydrophobicity of the resulting hybrid aerogel still hindered its application in biological environments.

By using tetrafunctional silanes like tetramethylorthosilicate $\left(\mathrm{Si}\left(\mathrm{OCH}_{3}\right)_{4}\right.$, TMOS $){ }^{16,30}$ as a silane source of hybrid, the macroscopic phase separation during gelation was significantly circumvented. However, the methanol byproducts released from the hydrolysis and condensation reactions caused an $\alpha$ helix- to- $\beta$-sheet transformation in the SF component of the gel and subsequently caused a shrunk, stiff, and hardly degradable final hybrid gel product. ${ }^{16}$ The stiffness in this hybrid aerogel was avoided using the silane coupling agents $(\mathrm{OR})_{3} \mathrm{Si}-\mathrm{R}^{\prime}$. In this case, the coupling agent has not only mediated the covalent interactions between SF and silica but also increased the mechanical resiliency of the gel due to the presence of flexible $R^{\prime}$ groups. Nevertheless, the presence of the nonhydrolyzable $-\mathrm{Si}-\mathrm{C}$ bond, ${ }^{45}$ also known as a nondegradable bond, in the formed gel structure was still problematic for BTE applications. In this study, one-step solgel processing of tetraethyl orthosilicate $\left(\mathrm{Si}\left(\mathrm{OCH}_{2} \mathrm{CH}_{3}\right)_{4}\right.$, TEOS) with SF in the presence of the acid catalyst (acetic acid), and a minute amount of the surfactant, CTAB, as a phase separation suppressing agent, appears to be more appealing. As with later, the polarity difference in the gel components and subsequent precursors' demixing in the aqueous phase have been substantially circumvented. This is also evident from homogenous (molecularly) distribution of network elements in the TEM-elemental mapping as shown at Figure $2 \mathrm{~d}$. Importantly, the resulting final gel has very good structural stability in the aqueous and cell media (cf. Figure 1) with a very slow disintegration rate.

SF sol-gel transition occurs through inter- and intrachain hydrogen bonding or physical cross-linking between the peptide chains in the presence of the acid catalyst. ${ }^{46}$ During gelation, some of the $\alpha$-helix structures in the SF polymer chains will also partially be transformed into the $\beta$-secondary crystalline structure as a mechanically more stable conformation and therefore toughen the obtained gel. ${ }^{46}$ Due to the availability of abundant various functional groups in the SF, the silica phase is incorporated into the SF network in different ways. A typical example might be based on covalent bonds, hydrogen bonding, and/or dipole-dipole interactions (cf. Figure 3$).^{28}$ The more probable covalent interactions, as seen in the solid-state MAS ${ }^{1} \mathrm{H}$ NMR spectrum in Figure $3 \mathrm{~b}$, is through condensation of abundant surface silanol groups $-(\mathrm{Si}-\mathrm{OH})$ with dangling hydroxyl functionalities of the SF network (e.g., with serine amino acids) to form $\equiv \mathrm{Si}-\mathrm{O}-$
$\mathrm{CH}_{2}-$ (Ser), $\delta: 3.3 \mathrm{ppm}$. On the other hand, the silane sol-gel polymerization in the sol mixture is followed simultaneously by formation of different condensed silica species designated at ${ }^{29} \mathrm{Si}$ CP-MAS NMR spectroscopy, Figure $3 c$, as $\mathrm{Q}_{n}$ peaks, $\mathrm{Q}_{4}$, $(\delta:-110 \mathrm{ppm}), \mathrm{Q}_{3},(\delta:-99 \mathrm{ppm})$, and $\mathrm{Q}_{2}(\delta:-91 \mathrm{ppm})$, where $n$ is the number of $\equiv \mathrm{Si}-\mathrm{O}-\mathrm{Si} \equiv$ bridges. During the silane gelation, a network of particles forms, which is "glued" together by the secondary phase of the silk fibroin network and therefore forms an interpenetrated network of silica-SF. ${ }^{16}$ Thermogravimetric analysis as shown in Figure $3 \mathrm{~d}$ indicates that the silica-SF aerogel hybrids are thermally stable up to $\sim 253{ }^{\circ} \mathrm{C}$, which is relatively similar to the other aerogel composites obtained with other biopolymers like pectin and cellulose. $^{27,29} \mathrm{SF}$ and the nonreacted ethoxy moieties in the network decompose around 253 and $395{ }^{\circ} \mathrm{C}$, respectively, with the SF polymer comprising $22 \%$ of the overall mass of the aerogel scaffold.

The ${ }^{1} \mathrm{H}-{ }^{29} \mathrm{Si}$ heteronuclear correlation (HETCOR) MAS NMR technique in Figure 4 confirms the appropriate

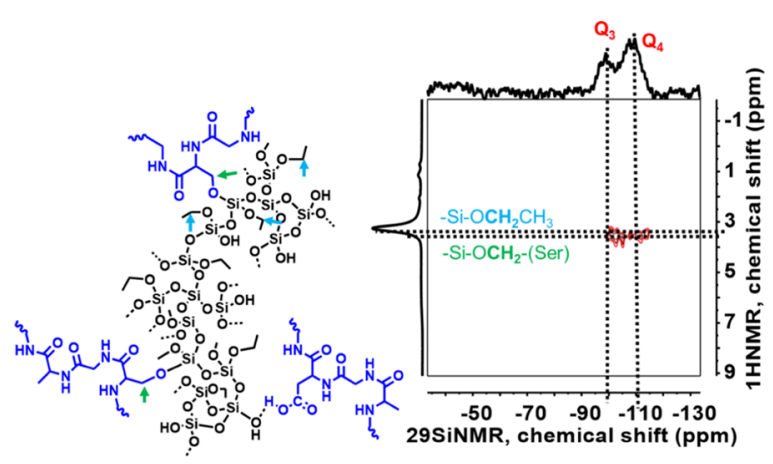

Figure 4. ${ }^{1} \mathrm{H}-{ }^{29} \mathrm{Si}$ heteronuclear correlation MAS NMR spectroscopy of the silica-SF aerogel.

molecular proximity of network constituents, SF, and silica in the hybrid structure through the coupling of SF protons with $\mathrm{Si}$ atoms. The correlation of methylene protons in the side chain of the SF network (serine and threonine, $-\mathrm{CH}_{2} \mathrm{OH},{ }^{1} \mathrm{H}$ NMR) with silicon atoms $\left(Q_{4}, Q_{3},{ }^{29} \mathrm{Si} N M R\right)$ of the silica network shows cross-peaks that further reflect the formation of molecularly mixed SF and silica domains instead of formation of separated individual SF and silica-enriched domains in the composites. This kind of correlation was also observed in our previous studies with the other silane phases (TMOS and MTMS) cogelled with the SF polymer. ${ }^{16,27,28}$ In general, this technique provides a broad view regarding the homogenous molecular scale mixing of the SF with silica/silsesquioxane phases regardless of covalent or noncovalent interactions. ${ }^{27}$

3.3. Silica-SF Aerogel Scaffold Biological Properties (in Vitro): Cell Viability, Attachment, Morphology, Protein Adsorption, Hemocompatibility, Biodegradability, and Biomineralization Studies. 3.3.1. Cell Viability. The 14 day MTT assay study shows that the silica-SF aerogel scaffold extracted medium possesses minimum cytotoxicity against osteoblast cells, which was comparable to those of the control and the blank mediums (Figure 5a). Not only did the medium collected from the incubated scaffold's degradation product did not cause any toxicity but also the growth and proliferation of osteoblasts on day 7 and day 10 were even better than that in the negative control and fresh medium. This suggests that the degradation or leaching product of the scaffold not only was nontoxic but also increases 
(a)
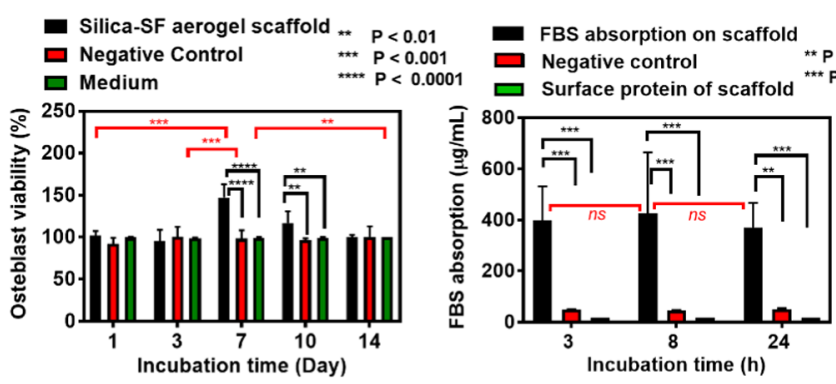

(d)
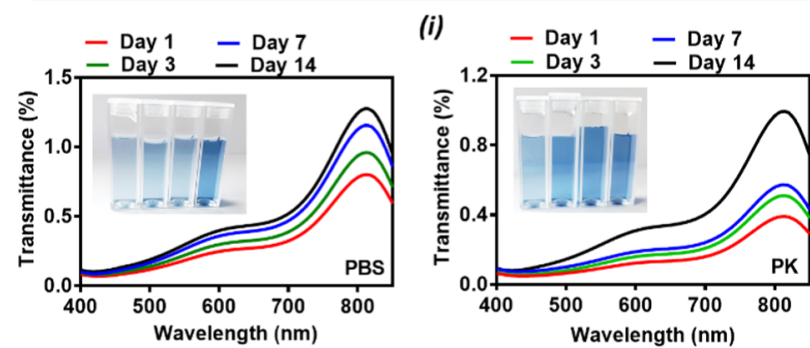

(iii)
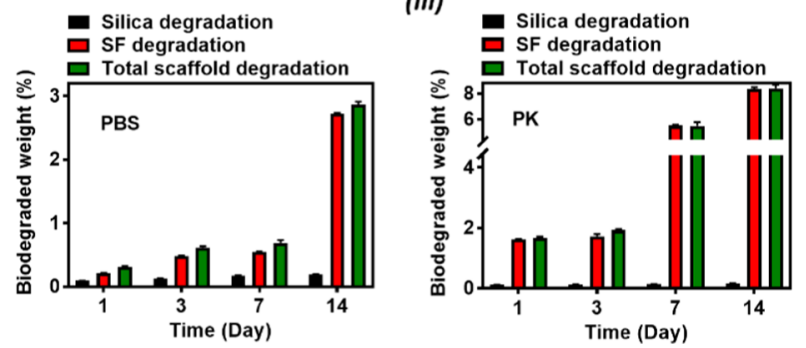

(b)

(c)
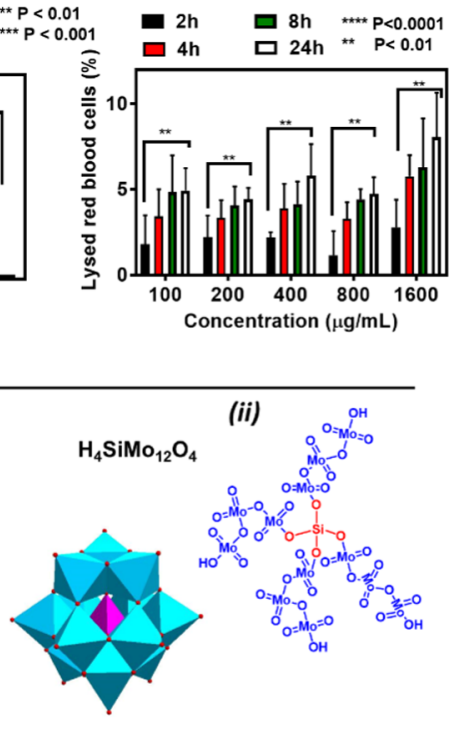

(e)

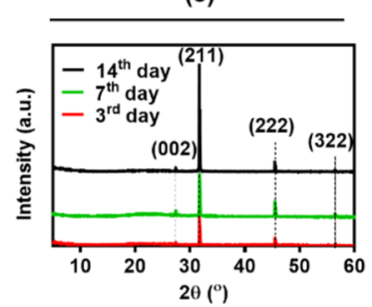

Figure 5. (a) Cell toxicity, (b) protein adsorption, (c) hemolysis, and (d) degradation studies for silica and SF component, (i) including the structure of the silicomolybdic acid (SMA) complex (ii) and its UV-visible spectra in different degradation solvents, phosphate-buffered saline (PBS), and proteinase K (PK); (e) X-ray diffraction (XRD) diffractogram for biomineralization of the silica-SF aerogel scaffold.
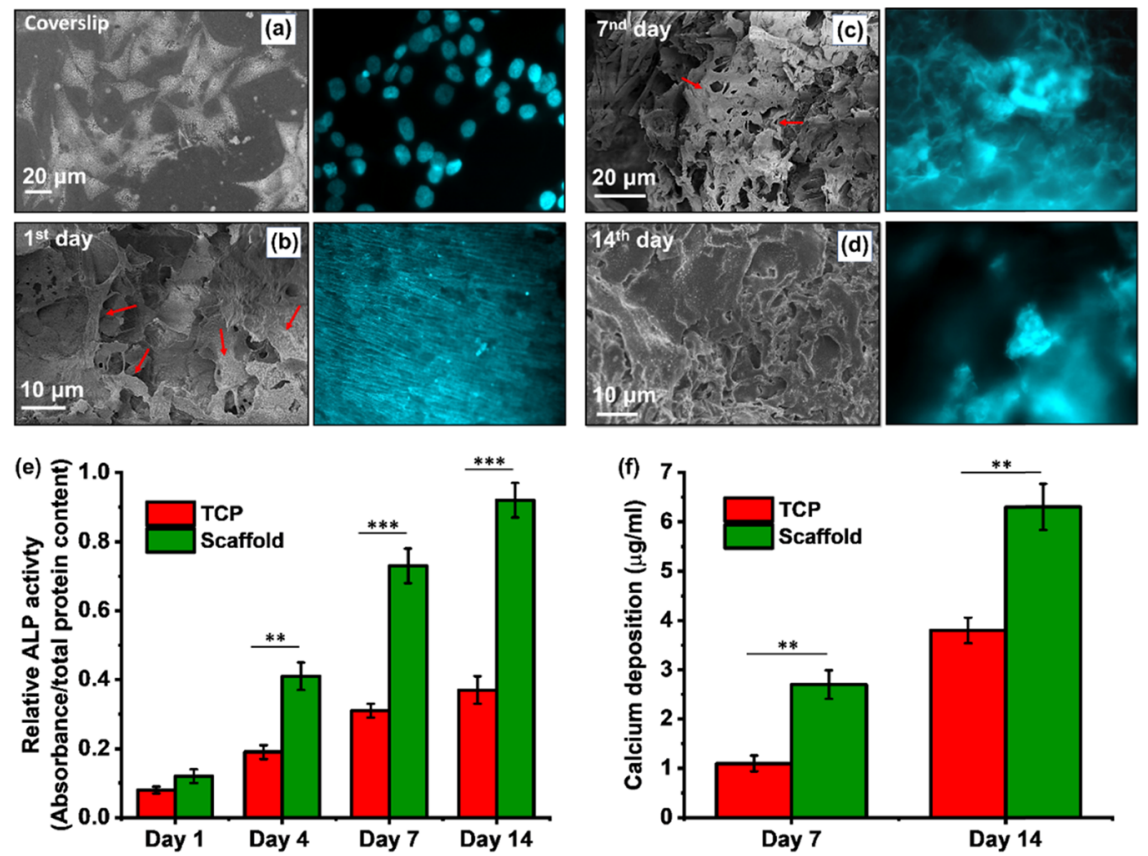

Figure 6. (a-d) SEM and fluorescence microscopy images (Hoechst 33342 staining) of cell growth and attachment on the scaffold over 14 days. (e) Alkaline phosphatase (ALP) activity and (f) calcium content of MG-63 cultured on the scaffold for 14 days. Statistical comparisons were performed with respect to $\beta$-tricalcium phosphate (TCP), which represents the cells grown in the two-dimensional culture flask. 
the proliferation and growth of osteoblasts compared to the blank medium.

3.3.2. Protein Adsorption. In tissue engineering, the adsorbed proteins on the scaffold or implant surface are the crucial regulators of many key signaling pathways. Namely, adsorbed protein can give signals to the cells' integrin and boost cell adhesion to the scaffolds' surface. ${ }^{47}$ Adsorption of the FBS on the silica-SF aerogel scaffold surface was investigated at three time points of 3,8 , and $24 \mathrm{~h}$ with the BCA assay to quantify the amount of the adsorbed protein. As is seen from Figure $6 \mathrm{~b}$, the initial average protein adsorbed on the aerogel surface is high $\left(400 \mu \mathrm{g} \mathrm{mL}^{-1}, 3 \mathrm{~h}\right)$, which then slightly increased to $430 \mu \mathrm{g} \mathrm{mL}^{-1}$ after $8 \mathrm{~h}$ of incubation and subsequently dropped to $370 \mu \mathrm{g} \mathrm{mL}^{-1}$ after $24 \mathrm{~h}$. The extent of the protein-biomaterial interaction is largely defined by the pore structure, surface charge, and surface roughness. ${ }^{44}$ The dual meso-macroporous character in the aerogel scaffold associated with high internal surface area $\left(S_{\mathrm{BET}}=433 \mathrm{~m}^{2}\right.$ $\mathrm{g}^{-1}$ ) renders its surface highly prone to FBS protein adsorption. ${ }^{47}$ On the other hand, we expect overall positive surface charge for the synthesized silica-SF aerogel due to the used acid catalyst in the sol-gel reaction, which further augmented the adsorption of negatively charged BSA proteins of FBS. However, for $24 \mathrm{~h}$, due to the slight surface erosion of the scaffold upon degradation, the protein adsorption slightly declined.

3.3.3. Hemocompatibility. The acceptance of biomaterials by the host tissue without provoking any adverse or undesirable effect, e.g., without lysing of the red blood cells, is known as biocompatibility. ${ }^{48}$ The silica-SF aerogel matrix causes a minute amount of hemolysis (cf. Figure 5c). The level lies at the range of nonhemolytic to slightly hemolytic $(<2$ to $2-8 \%$ ) according to the standard hemolytic index (ASTM F756-00(2000)). ${ }^{44}$ Our hemolysis data imply that the silica-SF aerogel is clinically implantable due to minimal effect on the lysis of RBCs, which can cause the release of procoagulant factors and consequently affect the blood flow and induce thrombogenesis. ${ }^{49}$

3.3.4. Biodegradation. Biodegradability within an acceptable time without the release of any harmful metabolic products is one of the most important features of biomaterials as it enables incremental replacement of the scaffolding material by newly formed functional tissue. The biodegradation rate of a biomaterial depends largely on its composition and $3 \mathrm{D}$ structure. ${ }^{50}$ Since the silica-SF aerogel scaffold is highly porous (94\%), it aids the enzyme to access to the internal structure and facilitate its biosorbability. The degradability of the SF component of the scaffold was monitored through incubation of the scaffold with PBS and PK (proteolytic enzyme) solutions under a slight agitation (100 rpm, $37{ }^{\circ} \mathrm{C}$ ) and by monitoring the scaffold's overall weight loss in the scaffold at each time point. Simultaneously, the degradation of silica into the silica species, e.g., silicic acids, $\mathrm{Si}(\mathrm{OH})_{4}$, in the PBS and PK supernatants for each time point was also studied through the silicomolybdic acid (SMA) spectrophotometric method (cf. Figure 5d-i,ii). The SMA method allows one to monitor the presence of monomeric silicic acids through formation of the blue heteropoly acid, silico-12-molybdic acid $\left(\mathrm{H}_{4} \mathrm{SiMo}_{12} \mathrm{O}_{40}\right.$ cf. Figure 5d-ii) complex, which has an absorbance band at $\lambda=810 \mathrm{~nm}$. As shown in Figure $5 \mathrm{~d}-\mathrm{i}$, an intensity increase in the UV-vis spectra can be visually confirmed with an increase in the color intensity of the blue SMA complex at higher incubation times. Particularly, the intensity of blue complex's color is proportional to the concentration of degraded silicate species in the solution. For 14 days of incubation, $0.22 \%$ of silica is degraded in PBS, but a lower degradation quantity $(0.18 \%)$ is observed in the case of PK due to the possibility of interaction of the enzyme with the molybdate reagent, which prevented SMA complex formation. Instead, in 14 days, SF degradation in PK ( $8 \%$ degradation) is higher than that observed in PBS solution (2.7\% degradation) (cf. Figure 5d-iii). Previous studies showed that B. mori scaffold sponges degraded quite faster (within 1 month), leaving the gap early without the formation of the neotissue. ${ }^{51}$ The hybridization of SF with silica seems to contract high degradability of SF and keeps the balance between the scaffold degradation and in vivo new tissue formations. The fate of these released degradation products may follow two paths: either remain in the local tissue or degraded with alveolar macrophage. ${ }^{44}$

3.3.5. Biomineralization. The bonelike hydroxyapatite (HAp, $\left.\mathrm{Ca}_{10}\left(\mathrm{PO}_{4}\right)_{6}(\mathrm{OH})_{2}\right)$ crystal formation on the scaffold surface was confirmed with the XRD diffractogram at Figure 5e for different immersion times in the simulated body fluid (SBF). Except the peaks masked by broad characteristic peaks of silk fibroin at 21 and $24^{\circ}$, the characteristic peaks at $26.5^{\circ}$ $(0,0,2), 31.9^{\circ}(2,1,1), 45.5^{\circ}(2,2,2)$, and $56.6^{\circ}(3,2,2)^{44}$ significantly match with the standard HAp crystallographic planes enlisted in JCPDS card number 09-0432. These results are in line with our observation in the SEM study in Figure S3 and confirm the ability of our fabricated conductive silica-SF aerogel scaffold to form apatite in a short time period. The SEM images show a significant change in the micromorphology of the scaffold matrixes with respect to the plain scaffold (Figure 2a), where different amounts and sizes of $\mathrm{Ca}-$ $\mathrm{P}$ salts are formed with immersion in SBF. Also, SEM micrographs revealed significant changes in the morphology of HAp from small aggregates of particles (3rd day) to micrometric-sized clusters of $\mathrm{Ca}-\mathrm{P}$ crystals at higher incubation times (14th day). The elemental composition analyzed by energy-dispersive X-ray analysis (Figure S3) is also found to be similar to the stoichiometric ratio of HAp crystals.

The formation of $\mathrm{Ca}-\mathrm{P}$ crystals indicates the surface bioactivity of silica-SF scaffolds and their ability to absorb $\mathrm{PO}_{4}{ }^{3-}$ and $\mathrm{Ca}^{2+}$ electrostatically. The surface silanol groups of nanostructured silica in the scaffold can attract $\mathrm{Ca}^{2+}$ cations of SBF and create a surface layer with positive charge, which can then adsorb $\mathrm{PO}_{4}{ }^{3-}$ and make the apatite nucleate and grow.

3.3.6. Cell Attachment, ALP Activity, and Mineralization Assessment. It is already known that the osteoblast is highly receptive to the surface chemistry, roughness, and energy of the materials. It is expected that highly porous character and the presence of the nanostructured silica together with the SF fibrous nature ultimately increase the surface topography and therefore increase the cellular interaction. On the other hand, as the SF in the scaffold tended to swell in the medium (swelling ratio: $22.1 \%$ after $24 \mathrm{~h}$ ), the structure became bigger in size and the cells inclined into the scaffolds. Therefore, as can be seen from SEM micrographs and fluorescence images of Hoechst 33342 stained attached cells (cf. Figure 6a-d), the silica-SF aerogel supports osteoblast cell growth and proliferation up to 14 days. On day 1 , the cells started to attach to the aerogel scaffold surface with almost the same morphology as seen on the surface of coverslips, as a reference, and the scaffold microstructure is quite different than what is observed in a plain scaffold (see also Figure $2 \mathrm{a}$ ). On day 7 , it 
(a)

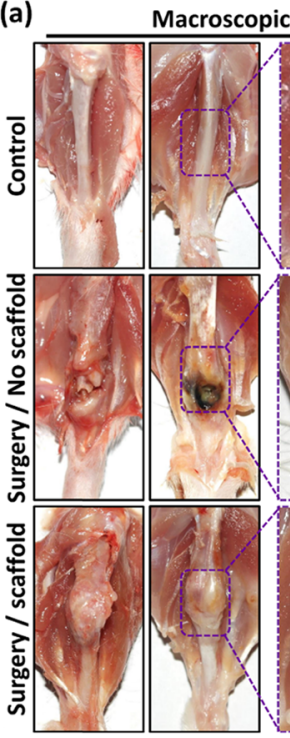

(b)

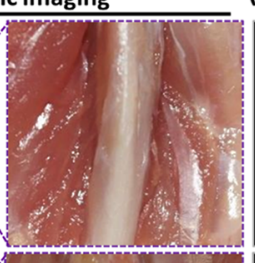

(b) $\quad \mu-\mathrm{CT}$ imaging

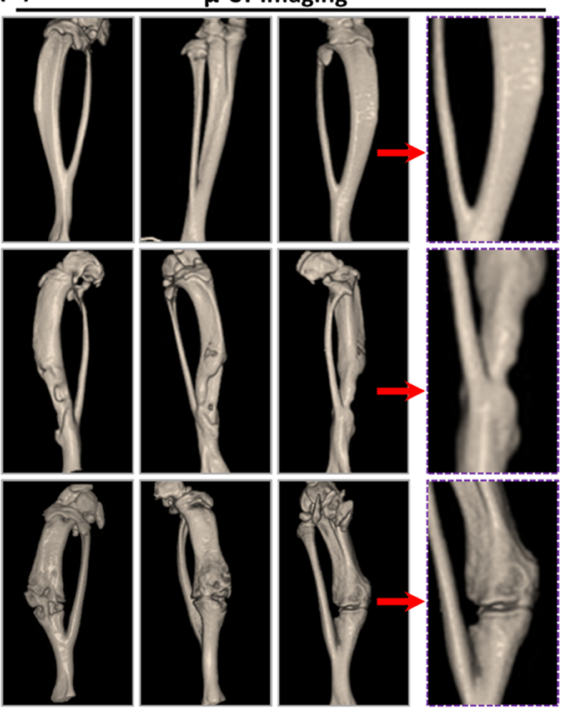

(c)
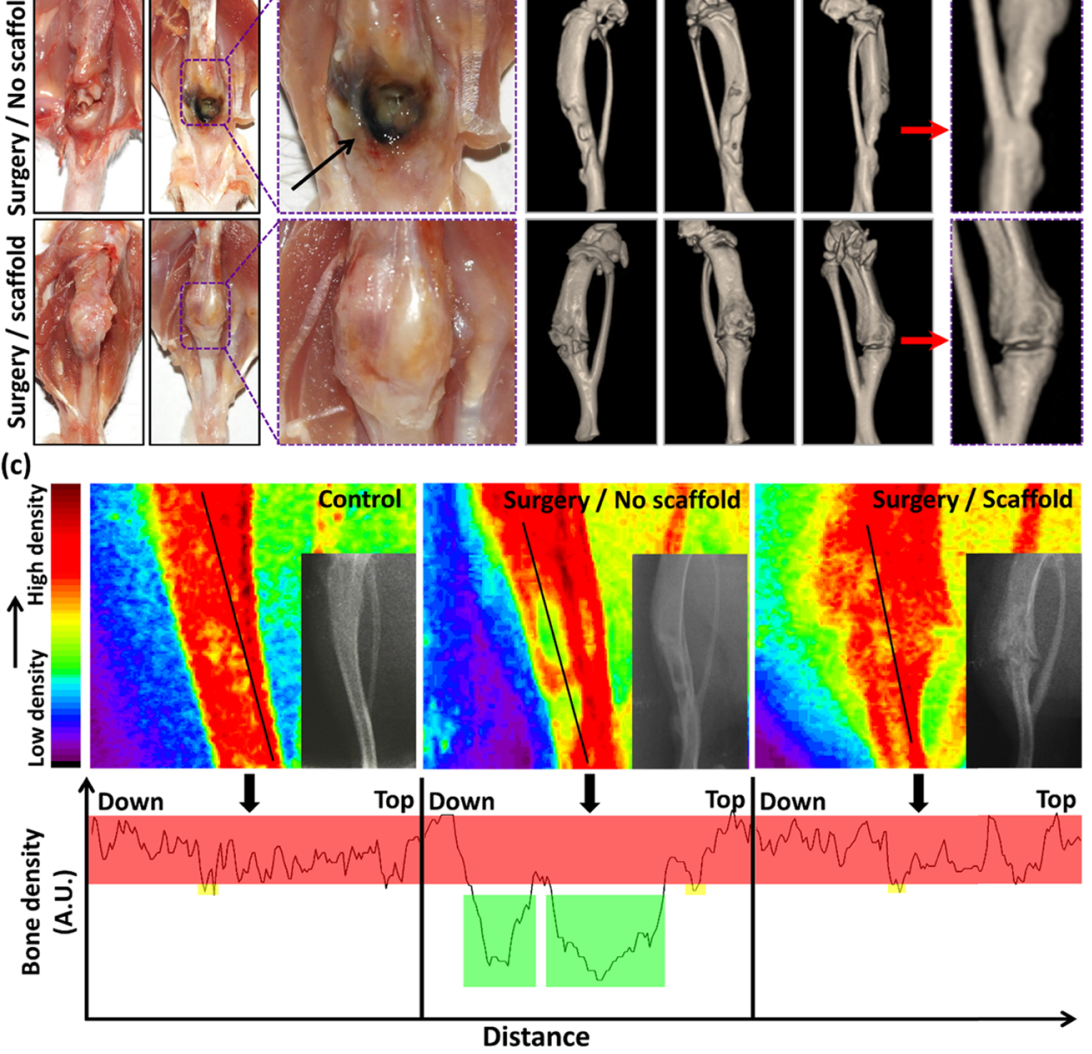

Distance

Figure 7. (a) Macroscopic view of the scaffold-implanted site after 25 days of placement in the region of the rat femur. (b) Micro-CT images of the bone in the control group without creating any defect as well as defect sites without and with scaffold after 25 days of surgery and implantation. The yellow area shows the areas without bone formation in the animals with bone defect but no scaffold implantation. (c) Counterplot color-based analysis of the bone density based on the radiographic images of the different tested groups shown in the bottom-right area of each counterplot image. The red area represents high density of the bone, whereas the green color demonstrates the parts without any bone formation. The bone density profile of the bone areas covered by the black line is drawn in counterplot color-based bone density analysis.

seems that the cellular actin filament substantially covers the surface of the scaffold with an increase in the cell-to-cell contact through cytoskeleton extension and occupies the interconnected $3 \mathrm{D}$ pores (see arrowheads in Figure $6 \mathrm{c}$ ). On day 14, a confluent cell layer with a rough surface covered the entire surface of the silica-SF aerogel scaffold, reflecting multilayer proliferation of MG-63 cells forming a uniform and compact ECM on the silica-SF aerogel.

As the early marker of bone cell differentiation, Figure $6 \mathrm{e}$ shows the ALP activity of cells cultured on the scaffold and TCP. On day 1, both groups demonstrated very low ALP activity, which represents poor differentiation of the cells into the osteoblast phenotype. Measurement of the ALP activity in the next days showed significantly higher ALP activity for the MG-63 cells seeded on the scaffolds than the blank TCP at each time point. In addition, mineralization was evaluated by the determination of calcium content, known as the late marker of cell differentiation toward osteoblasts. In line with the ALP activity test, Figure $6 f$ shows remarkably higher deposition of calcium on cells on days 7 and 14 for the scaffolds compared to TCP samples. These findings imply that the silica-SF aerogel scaffold, which possesses the main constituent of human bones, can provide an outstanding biomimic environment for the attachment of osteoblast cells as well as growth, proliferation, osteogenic differentiation, mineralization, and eventually osteogenesis for bone formation within a short time period.

3.4. In Vivo Studies. The main purpose of tissue engineering studies is to regenerate the structure and function of damaged tissues through the systematic trigger of molecular signaling of involved cells. A soft or hard three-dimensional structure made of degradable biomaterials is usually applied to provide a temporary template for cell proliferation in vivo. ${ }^{52}$ Therefore, we investigated the in vivo bone formation potential of the fabricated 3D silica-SF aerogel scaffold by macroscopic optical imaging, as well as X-ray and $\mu$-CT studies. ${ }^{53,54}$ The macroscopic images showed the new bone formation around and inside the implants (Figure 7a). Biocompatibility of the scaffold was approved since macroscopic degenerative change and necrosis were not observed in the defect site and around 

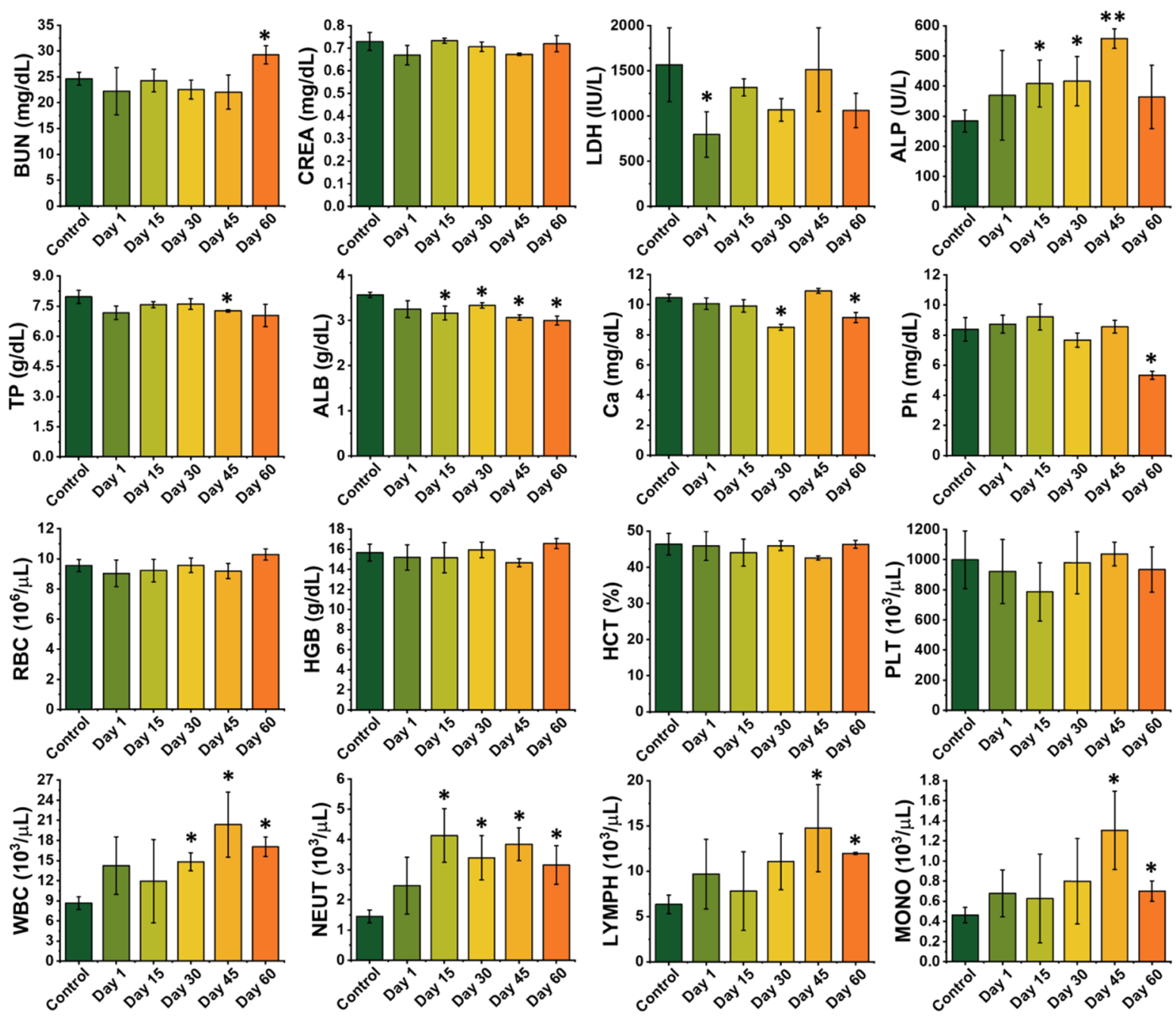

Figure 8. In vivo toxicity evaluation. Hematological index and biochemical blood analysis of rats at 1, 15, 30, 45, and 60 days post scaffold implantation are compared to the control group that was not subjected to surgery. The results show the mean and SD of BUN, CREA, LDH, ALP, TP, ALB, Ca, Ph, RBC, HGB, HCT, PLT, WBC, neutrophils (NEUT), lymphocytes (LYMPH), and monocytes (MONO) at different time points post scaffold implantation.

the boundary of the implanted scaffold at 25 days postimplantation. Sabri et al. ${ }^{55,56}$ have also previously substantiated the biocompatibility of the multichannel silica-based aerogel hybrid as a peripheral nerve repair scaffold in the rat model. In contrast, necrosis and cellular degeneration were observed in the animals that did not receive postsurgical scaffold implantation in the defect site of the femur. The images of the scaffold-receiving group also showed the integration of the scaffold into bone microstructure during the study period without any harmful effect on the surrounding tissues. In fact, the scaffold was well accepted by the local bone tissue without complications, such as infection, bleeding, or inflammation. In line with optical photographs, $\mu$-CT imaging exhibited the desirable progression of bone tissue regeneration in the scaffold-inserted animals (Figure $7 \mathrm{~b}$ ). The periosteum formation was complete in the animals receiving scaffold implantation, but very poor growth of the periosteum was observed in the defect site of the scaffold-free group. The X-ray radiography images showed a remarkable difference in the radiodensity of the defect site in surgery/no scaffold and surgery/scaffold animal groups, which proves the successful scaffold-mediated bone formation and favorable host-material interaction. The counterplot color-based bone density analysis of the radiography images demonstrated green areas in the red healthy and dense tissues of the bone, a sign of remaining bone defect after 25 days postsurgery in the animals that did not receive scaffold implantation (Figure $7 \mathrm{c}$ ). On the other hand, as an indicator of the mineralized callus synthesis and bone healing, the defect area of the bone was showing red color, and there was no sign of low-density bone (green color) in the scaffold-implanted animals. The corresponding bone density profiles of the black line shown in the counterplot color-based images of each group of the animals are also shown. The bone density of the scaffold-implanted area is similar to intact bone of the control group after 25 days, confirming rapid initiation of new and healthy bone formation.

A detailed examination of the in vivo toxicology of the scaffold was further performed over 60 days to identify its in vivo translation potential. Sixteen biochemical and hematological parameters were screened (cf. Figure 8). It was found that no meaningful changes were observed in red blood cells (RBCs), hemoglobin (HGB), hematocrit (HCT), and platelet (PLT) level for the scaffold-implanted group in comparison to the control group (Figure 8). On the other hand, the number of white blood cells (WBCs) increased. Since no infection was observed in the animals at the site of surgery, the increased 
values for WBCs can be associated with the inflammation and intelligent immunity due to the surgery performed on the animals that received scaffold implantation. A series of blood biochemical indexes and minerals, including blood urea nitrogen (BUN), creatinine (CREA), lactate dehydrogenase $(\mathrm{LDH})$, alkaline phosphatase (ALP), total protein (TP), albumin (ALB), calcium (Ca), and phosphor $(\mathrm{Ph})$, were examined. Among all, just ALP and ALB demonstrated significant abnormity compared to the control group. As functional indexes for the proper functioning of organs in the body of mice, other factors showed negligible changes between the control and scaffold-implanted groups. In general, we concluded that the tested scaffold does not have a negative impact on hematological, renal, and hepatic functions of the animals.

\section{CONCLUSIONS}

Hierarchically organized porous silica-silk fibroin aerogel hybrids with a honeycomb-like macropore morphology have been synthesized through a novel aqueous-based sol-gel process, unidirectional freeze-casting, and supercritical drying approaches. The hybrid aerogel of this study demonstrated a multitude of improved properties such as high porosity, high specific surface area with an interesting anisotropic micromorphology, and improved anisotropic mechanical behavior. The in vitro cell biology experiments within 14 days of incubation revealed that aerogel scaffolds are biocompatible, and their surface is very prone to osteoblast attachment and growth. In addition, due to the high specific surface area originating from their micro- and mesoporous microarchitecture, as well as the osteoconductive nature of the nanostructured silica component in the scaffold, the surface of the scaffold augmented the protein adsorption as well as the sedimentation of bone-type hydroxyapatite minerals, respectively. The in vivo bone formation studies supported the in vitro studies and substantiated the high potential of the aerogel implant to support the new bone tissue in the defect site without any negative biochemical and hematological toxic effects during bone formation. Finally, the fruitful biophysical and biological characteristics of the present aerogel composite may help in mimicking the in vivo physiological niche as well as in vitro bone disease tissue models.

\section{ASSOCIATED CONTENT}

\section{S Supporting Information}

The Supporting Information is available free of charge on the ACS Publications website at DOI: 10.1021/acsami.9b04283.

Descriptions on biodegradation, biomineralization, ALP assay, and protein adsorption quantification methods; some additional characterization data such as scaffold micrographs in different freeze-casting conditions, stress-strain curves, and biomineralization studies (PDF)

Videos of 3D reconstruction of silica-SF aerogel by X-ray microcomputed tomography at different cross sections (MP4)(MOV)

\section{AUTHOR INFORMATION}

\section{Corresponding Authors}

*E-mail: h.maleki@uni-koeln.de (H.M.).

*E-mail: m.a.shahbazi@helsinki.fi (M.-A.S.).

\section{ORCID}

Hajar Maleki: 0000-0002-2813-4700

Sanjay Mathur: 0000-0003-2765-2693

Nicola Hüsing: 0000-0003-2274-9779

\section{Notes}

The authors declare no competing financial interest.

\section{ACKNOWLEDGMENTS}

The synthesis part of this paper was conducted under the framework of Austrian Science Fund-(FWF) Lise-Meitner fellowship (project no. M2086-N34) at University of Salzburg, Department of Chemistry and Physics of Materials. Therefore, H.M. acknowledges financial support by the FWF. S.M. acknowledges financial support from Interreg ÖsterreichBayern 2014-2010 Project AB29 Synthese, Charakterisierung und technologische Fertigungsansätze für den Leichtbau "n2m" (nano-to-macro).

\section{REFERENCES}

(1) Melke, J.; Midha, S.; Ghosh, S.; Ito, K.; Hofmann, S. Silk Fibroin as Biomaterial for Bone Tissue Engineering. Acta Biomater. 2016, 31, $1-16$.

(2) Hutmacher, D. W. Scaffold-Based Tissue Engineering-Design and Fabrication of Matrices Using Solid Freeform Fabrication Techniques. In Advanced Manufacturing Technology for Medical Applications: Reverse Engineering, Software Conversion and Rapid Prototyping; Gibson, I., Ed.; John Wiley \& Sons, Ltd., 2005, Chapter 8.

(3) Murphy, C. M.; O’Brien, F. J. Understanding the Effect of Mean Pore Size on Cell Activity in Collagen-Glycosaminoglycan Scaffolds. Cell Adhes. Migr. 2010, 4, 377-381.

(4) Karageorgiou, V.; Kaplan, D. Porosity of 3D Biomaterial Scaffolds and Osteogenesis. Biomaterials 2005, 26, 5474-5491.

(5) Pircher, N.; Fischhuber, D.; Carbajal, L.; Strauß, C.; Nedelec, J.M.; Kasper, C.; Rosenau, T.; Liebner, F. Preparation and Reinforcement of Dual-Porous Biocompatible Cellulose Scaffolds for Tissue Engineering. Macromol. Mater. Eng. 2015, 300, 911-924.

(6) Maleki, H.; Durães, L.; García-González, C. A.; del Gaudio, P.; Portugal, A.; Mahmoudi, M. Synthesis and Biomedical Applications of Aerogels: Possibilities and Challenges. Adv. Colloid Interface Sci. 2016, 236, 1-27.

(7) Murphy, A. R.; Kaplan, D. L. Biomedical Applications of Chemically-Modified Silk Fibroin. J. Mater. Chem. 2009, 19, 64436450.

(8) Ding, Z.; Han, H.; Fan, Z.; Lu, H.; Sang, Y.; Yao, Y.; Cheng, Q.; Lu, Q.; Kaplan, D. L. Nanoscale Silk-Hydroxyapatite Hydrogels for Injectable Bone Biomaterials. ACS Appl. Mater. Interfaces 2017, 9, 16913-16921.

(9) Oliveira, A. L.; Sun, L.; Kim, H. J.; Hu, X.; Rice, W.; Kluge, J.; Reis, R. L.; Kaplan, D. L. Aligned Silk-based 3-D Architectures for Contact Guidance in Tissue Engineering. Acta Biomater. 2012, 8, $1530-1542$.

(10) Kim, U.-J.; Park, J.; Joo Kim, H.; Wada, M.; Kaplan, D. L. Three-dimensional Aqueous-Derived Biomaterial Scaffolds from Silk Fibroin. Biomaterials 2005, 26, 2775-2785.

(11) Ki, C.-S.; Park, S. Y.; Kim, H. J.; Jung, H.-M.; Woo, K.-M.; Lee, J.-W.; Park, Y.-H. Development of 3-D Nanofibrous Fibroin Scaffold with High Porosity by Electrospinning: Implications for Bone Regeneration. Biotechnol. Lett. 2008, 30, 405-410.

(12) Das, S.; Pati, F.; Choi, Y.-J.; Rijal, G.; Shim, J.-H.; Kim, S. W.; Ray, A. R.; Cho, D.-W.; Ghosh, S. Bioprintable, Cell-laden Silk Fibroin-Gelatin Hydrogel Supporting Multilineage Differentiation of Stem Cells for Fabrication of Three-Dimensional Tissue Constructs. Acta Biomater. 2015, 11, 233-246.

(13) Zhang, Y. S.; Yue, K.; Aleman, J.; Moghaddam, K. M.; Bakht, S. M.; Yang, J.; Jia, W.; Dell'Erba, V.; Assawes, P.; Shin, S. R.; Dokmeci, 
M. R.; Oklu, R.; Khademhosseini, A. 3D Bioprinting for Tissue and Organ Fabrication. Ann. Biomed. Eng. 2017, 45, 148-163.

(14) Farokhi, M.; Mottaghitalab, F.; Samani, S.; Shokrgozar, M. A.; Kundu, S. C.; Reis, R. L.; Fatahi, Y.; Kaplan, D. L. Silk Fibroin/ hydroxyapatite Composites for Bone Tissue Engineering. Biotechnol. Adv. 2018, 36, 68-91.

(15) Rockwood, D. N.; Preda, R. C.; Yücel, T.; Wang, X.; Lovett, M. L.; Kaplan, D. L. Materials Fabrication from Bombyx mori Silk Fibroin. Nat. Protoc. 2011, 6, 1612.

(16) Maleki, H.; Montes, S.; Hayati-Roodbari, N.; Putz, F.; Huesing, N. Compressible, Thermally Insulating, and Fire Retardant Aerogels through Self-Assembling Silk Fibroin Biopolymers Inside a Silica Structure-An Approach towards 3D Printing of Aerogels. ACS Appl. Mater. Interfaces 2018, 10, 22718-22730.

(17) Hüsing, N.; Schubert, U. Aerogels-Airy Materials: Chemistry, Structure, and Properties. Angew. Chem., Int. Ed. 1998, 37, 22-45.

(18) Yin, W.; Rubenstein, D. A. Biomedical Applications of Aerogels. In Aerogels Handbook; Aegerter, M. A., Leventis, N., Koebel, M. M., Eds.; Springer, 2011; pp 683-694.

(19) Szabó, B. A.; Kiss, L.; Manó, S.; Jónás, Z.; Lázár, I.; Fábián, I.; Dezső, B.; Csernátony, Z. The Examination of Aerogel Composite Artificial Bone Substitutes in Animal Models. Biomech. Hung. 2013, $52-63$.

(20) Salerno, A.; Diéguez, S.; Diaz-Gomez, L.; Gómez-Amoza, J. L.; Magariños, B.; Concheiro, A.; Domingo, C.; Alvarez-Lorenzo, C.; García-González, C. A. Synthetic Scaffolds with Full Pore Interconnectivity for Bone Regeneration Prepared by Supercritical Foaming Using Advanced Biofunctional Plasticizers. Biofabrication 2017, 9, No. 035002.

(21) Mallepally, R. R.; Marin, M. A.; Surampudi, V.; Subia, B.; Rao, R. R.; Kundu, S. C.; McHugh, M. A. Silk Fibroin Aerogels: Potential Scaffolds for Tissue Engineering Applications. Biomed. Mater. 2015, 10, No. 035002.

(22) Diaz-Gomez, L.; García-González, C. A.; Wang, J.; Yang, F.; Aznar-Cervantes, S.; Cenis, J. L.; Reyes, R.; Delgado, A.; Evvora, C.; Concheiro, A.; Alvarez-Lorenzo, C. Biodegradable PCL/Fibroin/ Hydroxyapatite Porous Scaffolds Prepared by Supercritical Foaming for Bone Regeneration. Int. J. Pharm. 2017, 527, 115-125.

(23) Martins, M.; Barros, A. A.; Quraishi, S.; Gurikov, P.; Raman, S. P.; Smirnova, I.; Duarte, A. R. C.; Reis, R. L. Preparation of Macroporous Alginate-based Aerogels for Biomedical Applications. J. Supercrit. Fluids 2015, 106, 152-159.

(24) Zhou, C.; Yang, K.; Wang, K.; Pei, X.; Dong, Z.; Hong, Y.; Zhang, X. Combination of Fused Deposition Modeling and Gas Foaming Technique to Fabricated Hierarchical Macro/Microporous Polymer Scaffolds. Mater. Des. 2016, 109, 415-424.

(25) Maleki, H.; Durães, L.; Portugal, A. An Overview on Silica Aerogels Synthesis and Different Mechanical Reinforcing Strategies. J. Non-Cryst. Solids 2014, 385, 55-74.

(26) Maleki, H.; Durães, L.; Portugal, A. Synthesis of Mechanically Reinforced Silica Aerogels via Surface-Initiated Reversible AdditionFragmentation Chain Transfer (RAFT) Polymerization. J. Mater. Chem. A 2015, 3, 1594-1600.

(27) Zhao, S.; Malfait, W. J.; Demilecamps, A.; Zhang, Y.; Brunner, S.; Huber, L.; Tingaut, P.; Rigacci, A.; Budtova, T.; Koebel, M. M. Strong, Thermally Superinsulating Biopolymer-Silica Aerogel Hybrids by Cogelation of Silicic Acid with Pectin. Angew. Chem., Int. Ed. 2015, 54, 14282-14286.

(28) Maleki, H.; Whitmore, L.; Hüsing, N. Novel Multifunctional Polymethylsilsesquioxane-Silk fibroin Aerogel Hybrids for Environmental and Thermal Insulation Applications. J. Mater. Chem. A 2018, 6, 12598-12612.

(29) Hayase, G.; Kanamori, K.; Abe, K.; Yano, H.; Maeno, A.; Kaji, H.; Nakanishi, K. Polymethylsilsesquioxane-Cellulose Nanofiber Biocomposite Aerogels with High Thermal Insulation, Bendability, and Superhydrophobicity. ACS Appl. Mater. Interfaces 2014, 6, 94669471.
(30) Maleki, H.; Huesing, N. Silica-Silk fibroin Hybrid (Bio)aerogels: Two-step Versus One-step Hybridization. J. Sol-Gel Sci. Technol. 2019, DOI: 10.1007/s10971-019-04933-4.

(31) Wubneh, A.; Tsekoura, E. K.; Ayranci, C.; Uludağ, H. Current State of Fabrication Technologies and Materials for Bone Tissue Engineering. Acta Biomater. 2018, 80, 1-30.

(32) Porrelli, D.; Travan, A.; Turco, G.; Marsich, E.; Borgogna, M.; Paoletti, S.; Donati, I. Alginate-Hydroxyapatite Bone Scaffolds with Isotropic or Anisotropic Pore Structure: Material Properties and Biological Behavior. Macromol. Mater. Eng. 2015, 300, 989-1000.

(33) Wang, D.; Romer, F.; Connell, L.; Walter, C.; Saiz, E.; Yue, S.; Lee, P. D.; McPhail, D. S.; Hanna, J. V.; Jones, J. R. Highly Flexible Silica/chitosan Hybrid Scaffolds with Oriented Pores for Tissue Regeneration. J. Mater. Chem. B 2015, 3, 7560-7576.

(34) Mitchell, G. R.; Tojeira, A. Role of Anisotropy in Tissue Engineering. Procedia Eng. 2013, 59, 117-125.

(35) Davidenko, N.; Gibb, T.; Schuster, C.; Best, S. M.; Campbell, J. J.; Watson, C. J.; Cameron, R. E. Biomimetic Collagen Scaffolds with Anisotropic Pore Architecture. Acta Biomater. 2012, 8, 667-676.

(36) Mathieu, L. M.; Mueller, T. L.; Bourban, P.-E.; Pioletti, D. P.; Müller, R.; Månson, J.-A. E. Architecture and Properties of Anisotropic Polymer Composite Scaffolds for Bone Tissue Engineering. Biomaterials 2006, 27, 905-916.

(37) Pircher, N.; Fischhuber, D.; Carbajal, L.; Strauss, C.; Nedelec, J.-M.; Kasper, C.; Rosenau, T.; Liebner, F. Preparation and Reinforcement of Dual-Porous Biocompatible Cellulose Scaffolds for Tissue Engineering. Macromol. Mater. Eng. 2015, 300, 911-924.

(38) Mieszawska, A. J.; Fourligas, N.; Georgakoudi, I.; Ouhib, N. M.; Belton, D. J.; Perry, C. C.; Kaplan, D. L. Osteoinductive Silk-Silica Composite Biomaterials for Bone Regeneration. Biomaterials 2010, 31, 8902-8910.

(39) Gaharwar, A. K.; Mihaila, S. M.; Swami, A.; Patel, A.; Sant, S.; Reis, R. L.; Marques, A. P.; Gomes, M. E.; Khademhosseini, A. Bioactive Silicate Nanoplatelets for Osteogenic Differentiation of Human Mesenchymal Stem Cells. Adv. Mater. 2013, 25, 3329-3336.

(40) Nishihara, H.; Mukai, S. R.; Yamashita, D.; Tamon, H. Ordered Macroporous Silica by Ice Templating. Chem. Mater. 2005, 17, 683689.

(41) Loh, Q. L.; Choong, C. Three-Dimensional Scaffolds for Tissue engineering Applications: Role of Porosity and Pore Size. Tissue Eng., Part B 2013, 19, 485-502.

(42) Zhang, Q.; Yang, X.; Li, P.; Huang, G.; Feng, S.; Shen, C.; Han, B.; Zhang, X.; Jin, F.; Xu, F.; Lu, T. J. Bioinspired Engineering of Honeycomb Structure - Using Nature to Inspire Human Innovation. Prog. Mater. Sci. 2015, 74, 332-400.

(43) Maleki, H.; Durães, L.; Portugal, A. Synthesis of Lightweight Polymer-reinforced Silica Aerogels with Improved Mechanical and Thermal Insulation Properties for Space Applications. Microporous Mesoporous Mater. 2014, 197, 116-129.

(44) Naskar, D.; Ghosh, A. K.; Mandal, M.; Das, P.; Nandi, S. K.; Kundu, S. C. Dual Growth Factor Loaded Nonmulberry Silk fibroin/ Carbon Nanofiber Composite 3D Scaffolds for In vitro and In vivo Bone Regeneration. Biomaterials 2017, 136, 67-85.

(45) Lyu, S.; Untereker, D. Degradability of Polymers for Implantable Biomedical Devices. Int. J. Mol. Sci. 2009, 10, 40334065

(46) Tseng, P.; Napier, B.; Zhao, S.; Mitropoulos, A. N.; Applegate, M. B.; Marelli, B.; Kaplan, D. L.; Omenetto, F. G. Directed Assembly of Bio-inspired Hierarchical Materials with Controlled Nanofibrillar Architectures. Nat. Nanotechnol. 2017, 12, 474.

(47) Zhang, K.; Fan, Y.; Dunne, N.; Li, X. Effect of Microporosity on Scaffolds for Bone Tissue Engineering. Regener. Biomater. 2018, 5, $115-124$.

(48) Shahbazi, M.-A.; Almeida, P. V.; Correia, A.; Herranz-Blanco, B.; Shrestha, N.; Mäkilä, E.; Salonen, J.; Hirvonen, J.; Santos, H. A. Intracellular Responsive Dual Delivery by Endosomolytic Polyplexes Carrying DNA Anchored Porous Silicon Nanoparticles. J. Controlled Release 2017, 249, 111-122. 
(49) Brockman, K. S.; Kizhakkedathu, J. N.; Santerre, J. P. Hemocompatibility Studies on a Degradable Polar Hydrophobic Ionic Polyurethane (D-PHI). Acta Biomater. 2017, 48, 368-377.

(50) Deb, S. Degradable Polymers and Polymer Composites for Tissue Engineering. In Cellular Response to Biomaterials; Silvio, L. D., Ed.; Woodhead Publishing Series in Biomaterials, 2009; Chapter 2, pp $28-60$.

(51) Naskar, D.; Ghosh, A. K.; Mandal, M.; Das, P.; Nandi, S. K.; Kundu, S. C. Dual Growth Factor Loaded Nonmulberry Silk fibroin/ Carbon Nanofiber Composite 3D Scaffolds for In vitro and In vivo Bone Regeneration. Biomaterials 2017, 136, 67-85.

(52) Langer, R. Tissue Engineering: Status and Challenges. e-biomed 2000, 1, 5-6.

(53) Sabri, F.; Sebelik, M. E.; Meacham, R.; Boughter, J. D., Jr.; Challis, M. J.; Leventis, N. In Vivo Ultrasonic Detection of Polyurea Crosslinked Silica Aerogel Implants. PLoS One 2013, 8, No. e66348.

(54) Allison, S. W.; Baker, E. S.; Lynch, K. J.; Sabri, F. In Vivo X-Ray Imaging of Phosphor-Doped PDMS and Phosphor-Doped Aerogel Biomaterials. Int. J. Polym. Mater. Polym. Biomater. 2015, 64, 823830.

(55) Sabri, F.; Boughter, J. D., Jr.; Gerth, D.; Skalli, O.; Phung, T.-C. N.; Tamula, G.-R. M.; Leventis, N. Histological Evaluation of the Biocompatibility of Polyurea Crosslinked Silica Aerogel Implants in a Rat Model: A Pilot Study. PLoS One 2012, 7, No. e50686.

(56) Sabri, F.; Gerth, D.; Tamula, G.-R. M.; Phung, T.-C. N.; Lynch, K. J.; Boughter, J. D., Jr. Novel Technique for Repair of Severed Peripheral Nerves in Rats Using Polyurea Crosslinked Silica Aerogel Scaffold. J. Invest. Surg. 2014, 27, 294-303. 